ACADEMIA ROMÂNĂ

Revue Roumaine de Chimie

http://web.icf.ro/rrch/
Rev. Roum. Chim.

2020, 65(7-8), 647-671

DOI: $10.33224 /$ rrch.2020.65.7-8.02

Review

\title{
AMPHIPHILES-METALS INTERACTIONS FOR APPLICATIONS IN MODERN TECHNOLOGIES: RECENT DEVELOPMENTS AND FUTURE PERSPECTIVES
}

\author{
Loredana MAIUOLO, ${ }^{a}$ Pietro CALANDRA,,${ }^{\mathrm{b}, *}$ Domenico LOMBARDO ${ }^{\mathrm{c}}$ and Elisabeta I. SZERB ${ }^{\mathrm{d}, *}$ \\ ${ }^{\mathrm{a}}$ Università della Calabria, Dipartimento di Chimica e Tecnologie Chimiche, via P. Bucci, Cubo 12/C, \\ 87036 -Arcavacata di Rende (CS), ITALY \\ ${ }^{\mathrm{b}}$ CNR-ISMN, Via Salaria km 29.300 Monterotondo Stazione (RM) ITALY \\ ${ }^{c}$ Consiglio Nazionale delle Ricerche, Istituto per i Processi Chimico-Fisici, 98158 Messina, ITALY \\ d "Coriolan Drăgulescu" Institute of Chemistry, Roumanian Academy, 24 Mihai Viteazu Bvd., 300223-Timişoara, ROMANIA
}

Received August 2, 2019

Amphiphiles play a pivotal role in the area of self-assembled structures and interesting additional features can be obtained if metal ions are involved. In this ambit, the development of smart materials benefits from the availability of stimuli-responsive supramolecular amphiphile assemblies where the disassembly back-processes has an inherently basic role providing reversible switching particularly useful in novel approaches and applications. In this tutorial review the basic concepts on self-assembly of traditional and novel amphiphilic molecules with metals are summarized and the more recent concepts of supramolecular assembly are presented. The aim of this contribution is to furnish to the reader a panoramic view of this exciting problematic clarifying what is meant with the concept of complexity and how the rich world of amphiphilic molecules is employed with metals for obtaining complex nanostructure-based systems with novel characteristics for applications in nanotechnology.

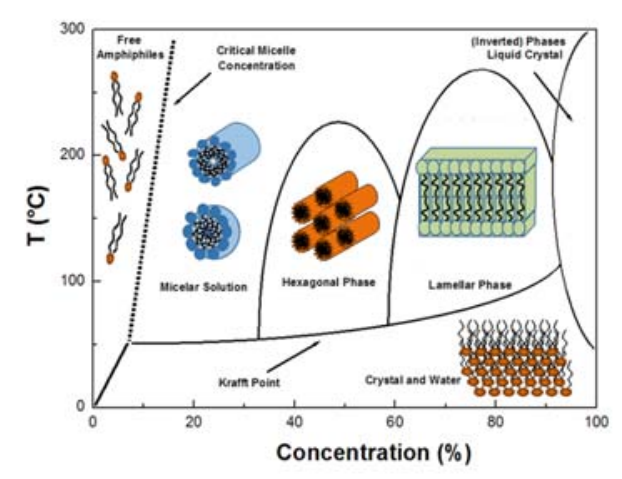

\section{INTRODUCTION}

Modern technology has an ever-increasing demand for nanomaterials. Not only because the small size of the nanostructures involved shops properties which cannot be found in the bulk corresponding materials, but also because the use of nanomaterials answers the need for miniaturization. For this reason, in the past big efforts have been made to understand the self- assembly mechanisms involved at the microscale with the aim at setting up efficient protocols for the piloted design of nanomaterials. Chemical species behave according to their own specific intermolecular, ionic, atomic etc. interactions showing sometimes disinclination to adopt the researcher's desired structural organization.

Only few types of molecules are capable to lead to useful self-assembled structures. Amphiphiles certainly play a pivotal role in this. They are

\footnotetext{
*Corresponding author: szella73@gmail.com; pietro.calandra@cnr.it
} 
synthetic or natural molecules with the peculiarity of possessing polar and apolar moieties within their molecular architecture. ${ }^{1}$ This triggers the arising of a wide scenario of possible intermolecular interactions like polar-polar, polarapolar, apolar-apolar, eventual directional $\mathrm{H}$ bonds, steric hindrance and so on. As a result, it is well known, they can self-assemble into a wide variety of structures including micelles, vesicles, nanotubes, nanofibers, and lamellae and these, in turns can even interact to form interacting structures at hierarchical length-scales characterized by emerging and specific properties and functions. At a lower level of complexity, it is spontaneous to exploit amphiphiles self-assembly to mimic biological systems ${ }^{2}$, but as a matter of fact amphiphiles have paved a way for other fields likes bionanotechnology, drug and gene delivery, bottom-up synthesis in materials science. ${ }^{3}$

Exciting functions can be imagined if metals are involved in this complex self-assembly process. Since the peculiar atomic structures are completely different from those of organic molecules, further and new features can be imparted in the systems: metal atoms are in fact usually dealt with as external to the "organic" chemistry so far represented by the surfactant, and are generally studied by inorganic chemists. For this reason, metals are the perfect candidates to enrich the potentialities of amphiphiles-based systems offering a way to the piloted design of novel materials with new properties and functions. Using a fundamental clue of physics of complexity, when two different materials are assembled together, new and emerging properties which cannot be traced back to the original constituents, usually arises.

To make an example, complexity has opened the door to biological systems where the assemble of lipids, proteins, and other macromolecules with their integrated actions allow the performance of highly specific cellular functions. But it must be admitted that in this regard, besides the organic part, the presence of metal atoms is necessary in order to make the structure as really "living".

While their self-assembly has attracted for decades considerable attention due to all the aforementioned applications, recent developments stimulated the combination of the simple approaches of amphiphile assembly with the advanced concept of supramolecular self-assembly for the development of more complex, hierarchical nanostructures. In this ambit, the development of smart materials benefits from the availability of stimuli-responsive supramolecular amphiphile assemblies where the disassembly back-processes has an inherently basic role providing reversible switching particularly useful in novel approaches and applications.

In this perspective, we summarize in this tutorial review the basic concepts on self-assembly of traditional amphiphilic molecules (such as surfactants, amphiphile-like polymers, or lipids) with metals and the more recent concepts of supramolecular assembly.

The aim of this contribution is to furnish to the reader a panoramic view of this exciting problematic clarifying what is meant with the concept of complexity and how the rich world of amphiphilic molecules is employed with metals for obtaining complex nanostructure-based systems with novel characteristics for applications in nanotechnology.

While the literature is full of contributions focusing on specific aspects of self-assembly, complexity, amphiphiles and metals, the present work wants to be an easy-to-read critical point of view which tries to interact with the reader's imagination to hopefully leading to the discovery of novel aspects and interconnections and ultimately stimulating new ideas and research.

\section{Self-assembly of amphiphiles, complex systems and emerging properties}

Although there is without any doubt plenty of works covering all the specific aspects involved in molecular self-assembly, recently we have given a panoramic view of the problematic facing the topic from a philosophical and critical point of view. We believe that a critically speculative treatment, in fact, would give a sight from the top of all the aspects involved in chemical self-assembly, a view which can be of benefit for the idealization and construction of novel devices with desired properties and functionalities for advanced specific applications. In this ambit, we have introduced the possibility that amphiphile-based systems could show complex behavior thanks to the wide scenario of simultaneously present interactions. In a complex system there is the emerging of novel properties which cannot be traced back to the characteristics of each single constituent of the system itself. In the present paragraph we will try to be suggestive more than comprehensive, referring the reader to the literature for the details 
of all the specific aspects in order to be an easy to read introduction of the topic.

A good starting point would be to admit that the term amphiphilicity is quite general. Any kind of molecule possessing polar and apolar part can be defined amphiphilic, no matter the relative volume of the two moieties. For example, amphiphiles are essential constituents of bile salts and cholesterol is a well-known substance useful for tuning the cell membrane fluidity. Its only polar group is a small $\mathrm{OH}$ group at the extreme side of a huge aromatic part. This in principle is enough to define it as amphihilic, since this oxydrilic part will tend to associate with other polar molecules or polar moieties of other molecules.

The non-covalent interactions may be H-bonds, van der Waals interactions, $\pi-\pi$ ones, electrostatic effects and so on. A more detailed description of the entities of such interactions is reported in reference 2 . Usually such interactions are responsible for the selfassembly processes in soft nanomaterials where the weakness of the involved forces (the so called "soft interactions" of the order of few $\mathrm{kJ} \cdot \mathrm{mol}^{-1}$ ) are counterbalanced by the involvement of a multiplicity of interaction sites which allows a wide scenario of structuring mechanisms. ${ }^{3-6}$ Generally speaking, since the interactions involved are usually soft the resulting structures give rise to the so-called soft-matter, which, of course, is a very general term including polymeric materials, membranes, quaternary structures of proteins, colloids, foams, detergents. ${ }^{7-8}$

Weak interactions mean that they are all comparable to the $\mathrm{K}_{\mathrm{B}} \mathrm{T}$ factor at room temperature, so interesting effects can be envisaged by changes in temperature: the driving force is usually thermodynamic and lies on the enthalpic term which drives a self-assembly process in general entropically unfavorable. This can drive the system to the equilibrium which is always to be intended as a dynamic equilibrium. In this continuous breaking and reforming process, the overall structure must then be considered only just the mere time- and space- averaged structure. This reversibility is one key-characteristic of supramolecular synthesis in soft matter which contrasts the conventional molecular synthesis of novel materials that involves the formation of covalent bonds. However, the weakness of the interactions involved is counterbalanced by the high number of these forces, producing, indeed, an overall effect which is strong enough to hold together different building blocks sometimes having different molecular structures. ${ }^{9-12}$ Advanced functional materials sometimes show also cooperative behaviour where the necessary step is the comprehension in a detailed treatment of the main forces acting in nanostructures (such as the hydrogen bonding, hydrophobic effects, screened electrostatic interaction, steric repulsion and van der Waals forces). ${ }^{13-15}$ The assemblies formed by surfactants can have different morphologies according to a high number of parameters: composition, surfactant concentration, type of amphiphiles as well as temperature and pressure. For example, ternary water/surfactant/oil systems can possess different local structures according to the relative amount of the three substances, such as lamellar, globular, cylindrical, bicontinuous and so on (Figure 1).

The state of a three-component system is dictated by its triangular phase diagram. Whereas for two-components (amphiphile/solvent system) simpler phase diagrams are usually used (Figure 2).

Generally, the amphiphile concentration is itself a pivotal parameter. With reference to the representative phase diagram shown in Figure 2, at very low concentration a predominant entropic driving force holds, so the molecules are dispersed randomly without any ordering. This is expected by simple thermodynamics for any kind of systems where one component is at very low concentration regime. Of course, this is generally obtained if no dynamic restrictions hinder the molecular motion. At a higher amphiphile concentration instead, selfassembled nano-structures are formed since the enthalpic contribution, which increases with the amphiphile concentration, overcomes the negative entropic one. If anisotropy is also present, liquid crystal phases can also appear. In the case of amphiphiles, the anisotropy is assured by the different solubility properties of the different ends of the amphiphiles together with a subtle balance of intermolecular interactions and steric interactions. ${ }^{16-18}$

Dense packing like hexagonal and lamellar phases can be formed in conditions of extremely high concentrations of amphiphile and liquid crystal phases can be formed. Generally, more complex phase behavior is observed in nonionic amphiphiles ${ }^{19}$ and the appearance of a cloud point can occur due to the interplay with collective phenomena involving a large number of macromolecules $^{20}$. In this situation it is obvious that temperature effects cannot be neglected. 


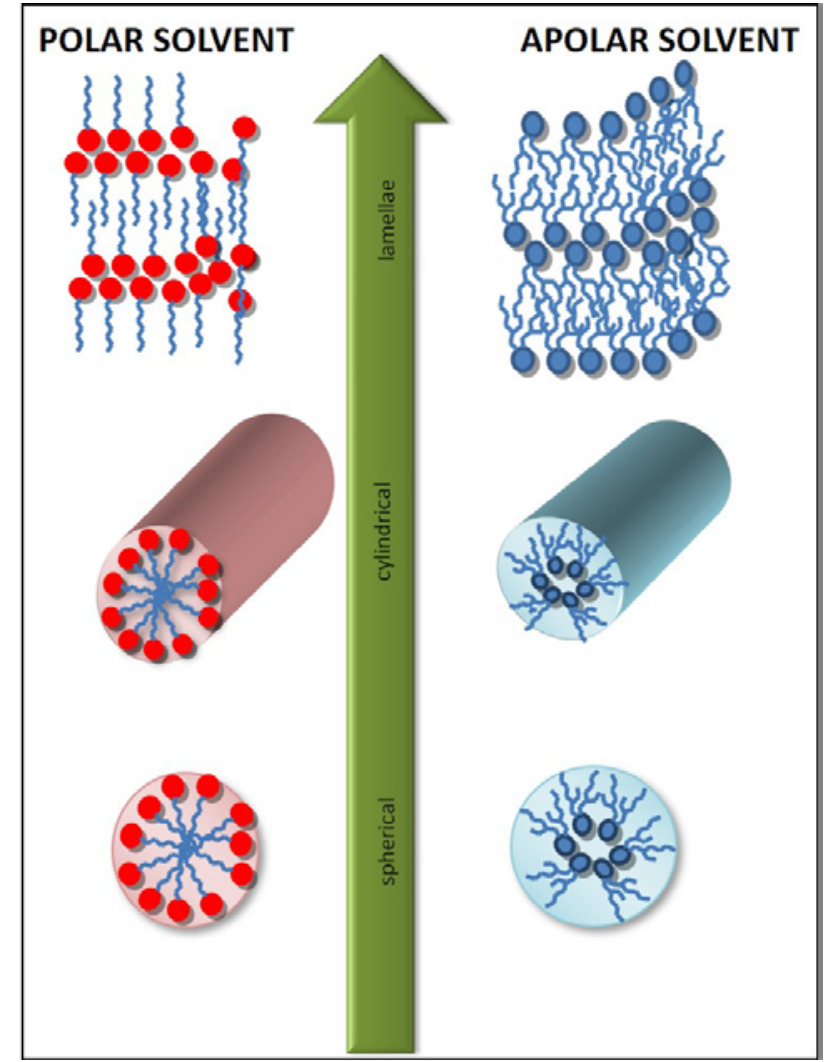

Fig. 1 - Supra-structures with various dimensionalities formed by the aggregation of amphiphiles: 0D (micelles), 1D (cylinders or cylindrical micelles), 2D (lamelles). These structures can be reversed (upper panel) or direct (lower panel) depending on the polarity of the solvent. In apolar solvent reversed structures are formed, in polar solvent direct structures are the stable ones.

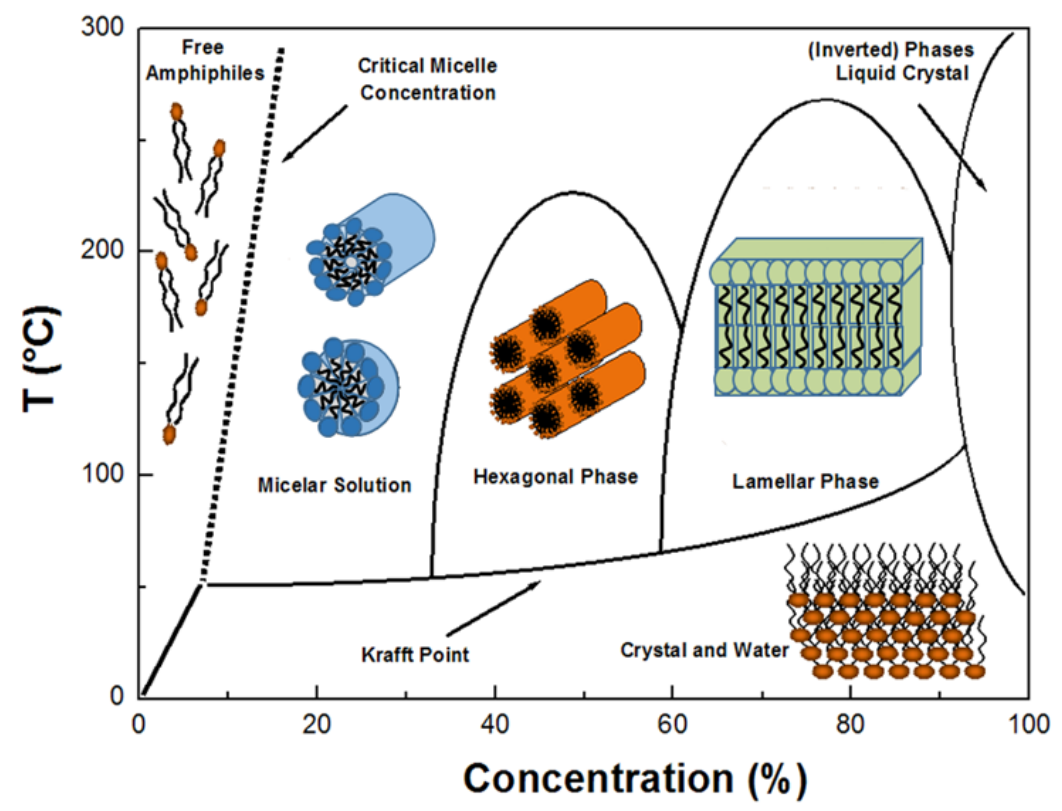

Fig. 2 - Typical phase diagram of apmphiphile dissolved in a solvent.

Given this scenario, it is obvious that such systems can be used as templates. Having spatial arrangements with different polarities they have been intensively used for metal-containing nanoparticle synthesis. Nanoparticles are generally formed in the aqueous regions of the system which behave as hydrophilic nanodomains/nanoreactors, and the spatial confinement dictated by the surfactant imposes their permanency: diffusion of the nanoparticle out of aqueous regions in fact 
would require a very high energy contribution and is enthalpically disadvantageous and does not occur. Some examples on the manipulation of metals through amphiphile-based systems for nanoparticle preparations are given in paragraph 5 .

\section{Amphiphiles for metal nanostructure synthesis}

Amphiphile-based systems have allowed the controlled synthesis of a wide number of inorganic nanoparticles. In the literature there is plenty of articles dealing with the nanoparticle synthesis by means of surfactant-based systems. Here we will deal with the microemulsions taken as representative since the clues are of general validity.

Metal atoms are present in a wide variety of materials. Pretty metal nanoparticles are synthesized by reduction of a metal-salt precursor: the precursor salt being polar, will segregate into the polar domain of the amphiphile-based system, and its reduction drives the formation of a solid metal nanoparticles. ${ }^{21}$ Semiconductors, like CdSe, $\mathrm{ZnS}$, are synthesized in similar way by mixing two water-in-oil microemulsions, one containing, in form of hydro-soluble salt the cation, and the other containing (in the same hydro-soluble form) the anion making the final semiconductor. The mixing of the two microemulsions, and the consequent intermicellar exchange of materials taking place as a consequence of the dynamical processes (which will be specified in the following), allow the two salts to come into contact, react and form the semiconductor. Other more sophisticated techniques are based intimately on the strategy of confining salts within the aqueous cores of reversed micelles. See for example the review by J. Eastoe et al. and references therein for a panoramic view. ${ }^{22}$

The role of amphiphiles in the preparation of metal nanoparticles is twofold: i) compartmentalization as a consequence of the amphiphile tendency to adopt specific supramolecular structures; ii) direct interaction of the amphiphile polar head with the metal, which offers further stabilization and force the metal to stay in close proximity to the polar headgroup. It must be pointed out that these two effects are interconnected and are the consequence of a modellization of the true system, nevertheless it is useful for didactical scopes to analyze them separately.

\section{Compartmentalizing structures}

The domains formed as a consequence of the polar/apolar nanosegregation can act as local, compartmentalizing nanoreactors, in few words exerting templating functions. Apart from the possibility of mutual interactions among nanoparticles allowing the emergence of novel features which are absent in the isolated ones ${ }^{23}$, microemulsions are considered as stable system and the polar domain as closed and rigid structures. It is important to point out that it is not the case, due to all the factors discussed in paragraph 1 and above all, the weakness of the interactions involved in surfactant-based systems. This makes all the structures evanescent and characterized by a wide variety of dynamical processes, each one with a characteristic time-scale: i) rotation dynamics of monomers within the micelle; ii) conformational change of monomers within the micelle; iii) micellar breaking-reforming; iv) Micellar shape change; v) lateral diffusion of monomers; vi) exchange of monomers with those in solution, vii) micelles fusion/scission; viii) intermicellar exchange of materials. Therefore, such structures must be considered only in terms of time- and space- averaged systems, being the micellar life timescale of the order of milliseconds.

The shape of such templates can be controlled. The analysis by Israelachvili ${ }^{24,25}$ allows to correlate specific amphiphile characteristics to the aggregate structure. It takes into account the so-called critical packing factor $(C \mathrm{pp})$ defined as:

$$
C \mathrm{pp}=V_{0} /\left(A_{\text {mic }} l_{c}\right)
$$

where: $V_{0}$ is the effective volume occupied by hydrophobic chains in the aggregate core, $l_{c}$ is the maximum effective length (critical chain length) and $A_{\text {mic }}$ is the effective hydrophilic headgroup surface area at the aggregate-solution interface.

The structures generated for the different $C p p$ values are reported in Table 1.

Table 1

Correlation between $C$ pp and structures generated

\begin{tabular}{c|c}
\hline Cpp & Structure \\
\hline$<1 / 3$ & spherical \\
$1 / 3-1 / 2$ & cylindrical \\
$1 / 2-1$ & vescicles (spherical or \\
1 & ellipsoidal) \\
$>1$ & lamellar \\
& inverse micelles \\
\hline
\end{tabular}


The increment of $C \mathrm{pp}$ value drives the system progressively from spherical aggregates to various structures. For example, vescicles, i.e. closed amphiphile bilayer structures with an internal cavity containing the dispersion solution can be formed by synthetic or natural phospholipids (liposomes) which are generally made up of one hydrophilic head and two hydrophobic tails. ${ }^{26,27}$ These structures resembles those formed in biological membranes. The micelles droplet radii are usually in the range of $5-50 \mathrm{~nm}^{28}$ while for vesicles the size usually ranges from $10 \mathrm{~nm}$ to 10 $\mu \mathrm{m}$, since concentric bilayer surfaces in an onionlike structure (hydrated multilayers) ${ }^{29-31}$ can hold.

It is worth pointing out that the precise description of aggregate morphology for amphiphiles with more complex topology is more difficult to rationalize due to the different involved intermolecular interactions and complex synergistic effects present. ${ }^{32,33}$ Effect of solvent remains, however predominant: polar solvent will drive to direct micelles with the polar heads pointing to the solvent, while apolar solvents will push to the formation of inverse micelles, with the amphiphile headgroup forming the core of the aggregates.

\section{Direct amphiphile-metal interaction}

If the amphiphile aggregate can be considered as the domain hosting the metal nanostructure, the direct interaction between amphiphile polar head with the metal ion can give further stabilization. This interaction must be of strength comparable or major to the interactions involved in the aggregate.

Ligands usually act as Lewis bases, i.e. electron density donors to the metal center which behave as Lewis acid. But this is not the only way. A method to classify the number and type of interactions between a metal and ligand is the Covalent Bond Classification. It has been proposed by Green and Parkin. ${ }^{34}$ Using their formalism, neutral two electron donor fragments are named L-type ligands. In this case the metal-ligand bond is a dative interaction. In the case of X-type ligands, one electron comes from both the metal and the ligand so the metal-ligand bond can be considered a covalent bond. Finally, if the metal is an electron density donor towards the ligand, these are named Z-type ligands. This type of dative interaction formally increases the valence state of the metal by two. The type and strength of the metal-ligand bonding involved will depend on several factors. Chemical arguments based on electrostatics and orbital overlap ${ }^{35}$ suggest that the estimation of hardness or softness of Lewis acid/base properties can give immediate information of the metal-ligand bond strength. Hard transition metals, such as high oxidation state complexes of the Group 3, 4, or 5 metals, as well as lanthanides, form strong bonds to hard Lewis basic ligands such as those featuring $\mathrm{N}$ - and O- donor atoms. ${ }^{36}$

Although there are some arguments about the fact that the bond strengths may not be correlated with bond lengths ${ }^{37}$ a generally adopted equation for calculating bond valences $(v)$ from bond lengths is:

$$
v=e^{\frac{R-d}{b}}
$$

where: $\mathrm{R}$ is the experimental single bond length, $\mathrm{d}$ is the bond distance and $\mathrm{b}$ the Brown Altermatt constant $(\mathrm{b}=0.37 \AA \hat{)})$. A bond length of $>3.5 \AA$ corresponds to a valence close to zero. The valence bond theory is simple and of practical use being also able to include long-range ionic effects, which could be of hard quantification with other calculations, like Madelung fields etc. ${ }^{38}$

Just to give an example, in $\left[\mathrm{CuCl}_{2}\left(\mathrm{NH}_{3}\right)_{2}\right]$, the $\mathrm{Cu}-\mathrm{N}$ bond is estimated to be around $90 \mathrm{~kJ} / \mathrm{mol}$, whereas in $\mathrm{Zn}-\mathrm{O}$ (taking into account similarities with $\mathrm{ZnO}$ and MOF-5 (i.e. $\left[\mathrm{Zn}_{4} \mathrm{O}\left(\mathrm{O}_{2} \mathrm{CC}_{6} \mathrm{H}_{4} \mathrm{CO}_{2}\right)_{3}\right]$ ) it has been suggested a value of around 180 $\mathrm{kJ} / \mathrm{mol}^{39}$ These values are to be compared to the typical H-bonds of few tens of $\mathrm{kJ} / \mathrm{mol}$ and a typical covalence bond (C-C) of $350 \mathrm{~kJ} / \mathrm{mol}$ suggesting that in the field of soft matter the metal-ligand strength is high and can constitute a driving force in self-assembly. It can be concluded that direct interaction between the amphiphile polar head with a metal ion can be of higher importance with respect to the bare templating role exerted by the amphiphile self-segregation into polar/apolar domain in establishing the overall amphiphilemetal structure. Therefore, if amphiphile selfassembly can stabilize organic molecules clusters, ${ }^{40,41}$ it has been observed that this is true also in the case of metal nanoparticles, where their high density (higher than that of organic clusters) would render their solubilization/stabilization quite difficult in liquid media.

The possibility of direct amphiphile-metal interaction allows other interesting applications which are representatively shown in the following paragraphs. 


\section{Supra-ordering}

Once nanoparticles are stabilized through surface functionalization with organic ligands or active surfaces a supra-arrangement into a higher level of complexity can be made. In fact nanoparticle organization into highly ordered arrays, allows the production of the so-called "metamaterials", which exhibit emerging and sometimes collective magnetic, optical and electronic behaviors, enabling their use in nanoelectronic and nanophotonic applications. ${ }^{42,43}$ In this ambit the organic-inorganic interface is of utmost importance. ${ }^{44}$ Surfactantassisted self-assembly can take place for a wide variety of materials: semiconductor nanoparticles, called "Quantum dots" which are fluorescent nanocrystals with sometimes higher performances with respect to those of conventional organic dyes or fluorescent proteins (large absorption coefficient, bright photoluminescence emission, narrow and symmetric emission profile, high photochemical stability); magnetic nanoparticle for bio applications, and core-shell structures for simultaneous magnetic resonance (MR) and fluorescence imaging, and for drug delivery. ${ }^{45,46} \mathrm{In}$ this ambit self-assemblies of magnetic iron oxide into organized structures (superparticles) show enhanced saturation magnetization, while avoiding the superparamagnetic-ferromagnetic transition. ${ }^{47}$ In addition to bio applications, nanoparticles in micelles have proven to be effective functional building block for further self-assembly into robust, highly ordered nanoparticle arrays for nanoelectronic or nanophotonic devices. ${ }^{48}$

Multi-compositional nanoparticles can be used as building blocks to obtain highly ordered super particles possessing multiple functions depending on the choice of the initial nanoparticles: in this case the number of applications are high and interestingly span over biomedical, photocatalytic, and optic/electric devices. ${ }^{49}$ However, for an interesting panoramic view of all these aspects the readers are referred to the review by Wei et al. ${ }^{50}$

\section{Other applications: miscellaneous}

The direct interaction eventually occurring between the surfactant polar head and metal ions constitutes a driving force in water purification field. In particular, solvent extraction process has been used for many years for separation of rare earths elements in industry (hydrometallurgy). ${ }^{51}$ This field has been widened by the progresses in nuclear industry where the recovery of plutonium uranium form liquid wastes has become a worldwide need inspiring a lot of work (see PUREX process).

Derivatives of phosphoric acid have been widely used: bis(4-ethylcyclohexyl) phosphoric acid has been used ${ }^{52}$ but bis(2-ethylhexyl) phosphoric acid (HDEHP) has been one of the most used extractants being effective also in Cobalt separation besides in lantanide separation. ${ }^{53,54}$ These authors also explored the effect of cosurfactant. It is interesting to notice that HDEHP has been defined "an excellent extractant of rare earth metal ions" in the article by Z. Yuan et al. ${ }^{55}$ who mixed it with a cationic trimethyltetradecylammonium hydroxide $(\mathrm{TTAOH})$ in water, generating a birefringent LR phase consisting of densely stacked multilamellar vesicles.

We would like to point out that given the peculiar self-assembly in amphiphilic systems, the assembled structures can exhibit also catalytic properties: Reinskje Talhout and Jan B. F. N. Engberts, for example, found this peculiar feature in mixtures of sodium alkyl sulfates and alkyltrimethylammonium bromides. ${ }^{56}$ For this reason we are prone to believe that this eventual catalytic properties possessed by self-assemble structures of amphiphiles, together with their natural tendency to bind metal, could make these substances an interesting class of materials to be tailored for specific applications in catalysis.

The alkylphosphate tendency to bind metals can cause the formation of a layer of opportunely oriented molecules onto metal surfaces: Guo et al. ${ }^{57}$ investigated the formation of triphenyl phosphate and bis-(2-ethylhexyl) phosphate films on iron surface using both experimental methods and molecular simulations. This phenomenon inspired their use as protective agent (inhibitors) towards tarnishing in silver. ${ }^{58}$

In many amphiphilic systems the subtle combination of the soft interactions at the nanoscale and at a molecular level can generate also soft nanostructured materials with relatively complex morphologies and characterised by a multi-stage organization process. In this mechanism a wide variety of molecules can be involved: dendrimers and vescicles ${ }^{59}$ block copolimers ${ }^{60}$ and amphiphiles whose organisation can give supra-amphiphiles ${ }^{61}$ with the overall result to obtain biomaterials through molecular self-assembly ${ }^{62}$ and complex matter. ${ }^{63}$ Those nano-structures present novel and complex structural, morphological ${ }^{64}$ and dynamic behaviour 
that can be exploited for specific (supra-)molecular functions, like synthesis of zeolites ${ }^{65}$ formation of peptides and proteins for nanotechnological applications ${ }^{66}$ including the preparation of protein fibres ${ }^{67}$ conductive fluids with novel properties of conductivity ${ }^{68}$ and inorganic metal-semiconductor nanoparticles with novel optical properties. ${ }^{69}$ In this ambit the presence of metal opens new scenarios in the design and fabrication of novel materials. ${ }^{70}$

\section{Synthesis of ad-hoc amphiphiles for binding metals}

\section{Simple amphiphiles}

Di-(2-ethylhexyl) phosphoric acid (HDEHP), tributyl phosphate (TBP), octanoic acid (OA) and bis-(2-ethylhexyl)amine (BEA) are just a few examples among the simplest amphiphilic molecules. Generally, they are commercial products with low cost and high purity. Obviously, chromatographic techniques may increase the purity degree, while desiccating agents, molecular sieves or zeolites may remove the water as impurity "captured" from polar heads of amphiphiles. Anyway, from a synthetic point of view, it is possible to realize various routes to synthesize these molecules, some by classic procedures of organic chemistry and others by more recent synthetic methodologies.

\section{Di-(2-ethylhexyl) phosphoric acid (HDEHP)}

Di-(2-ethylhexyl) phosphoric acid is prepared through the classical reaction between phosphorus pentoxide and 2-ethylhexanol (Scheme 1). ${ }^{71}$ This reaction produces, generally, a mixture of mono-, di-, and trisubstituted phosphates, from which HDEHP can be isolated based on solubility.

HDEHP is generally used as solvent extraction of uranium(VI) from aqueous acid or alkaline solutions by Dapex and Amex processes. ${ }^{72}$

\section{Tributyl phosphate (TBP)}

Synthetically, the preparation of tributyl phosphate consists of the reaction between $n$-butyl alcohol and phosphorus oxychloride in dry pyridine at room temperature (Scheme 2). ${ }^{73}$

Tributyl phosphate (TBP) is one of the widely used extractants for the removal of uranium(VI). More recently, TBP grafted carbon nanotubes were prepared to amplify the removal and recovery of $\mathrm{U}(\mathrm{VI}){ }^{74}$

A recent application in order to improve the extraction capability of vanadium(IV), (V) and (VI) is a resin impregnated at the same time with HDEHP and TBP. The results show that the soleTBP impregnated resins have no adsorption capability for V(IV), indicating that the adsorption of V(IV) is attributed to HDEHP. ${ }^{75}$

\section{Octanoic acid (OA)}

Various synthetic strategies are possible to prepare octanoic acid (OA) by classical organic reactions, starting from different precursors as 2octenoic acid, methyl octanoate or vinyl octanoate (Scheme 3). ${ }^{76-79}$ The reactions produced the final substrate with quantitative yield.

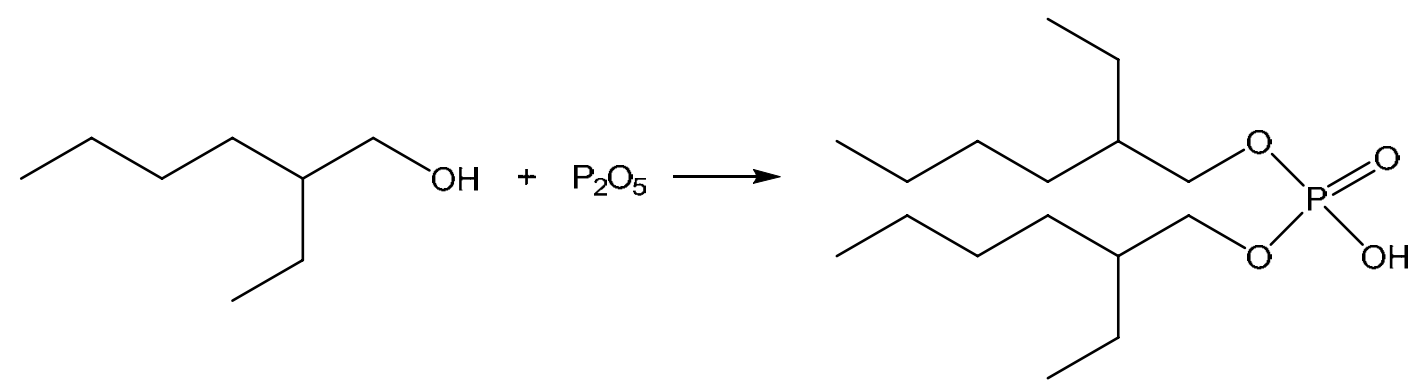

Scheme 1 - Classical synthetic procedure for HDEHP.

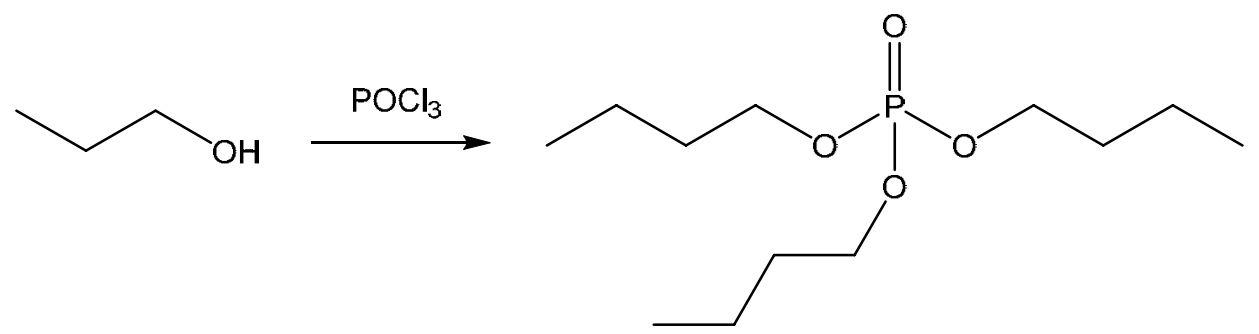

Scheme 2 - Synthetic procedure for TBP. 

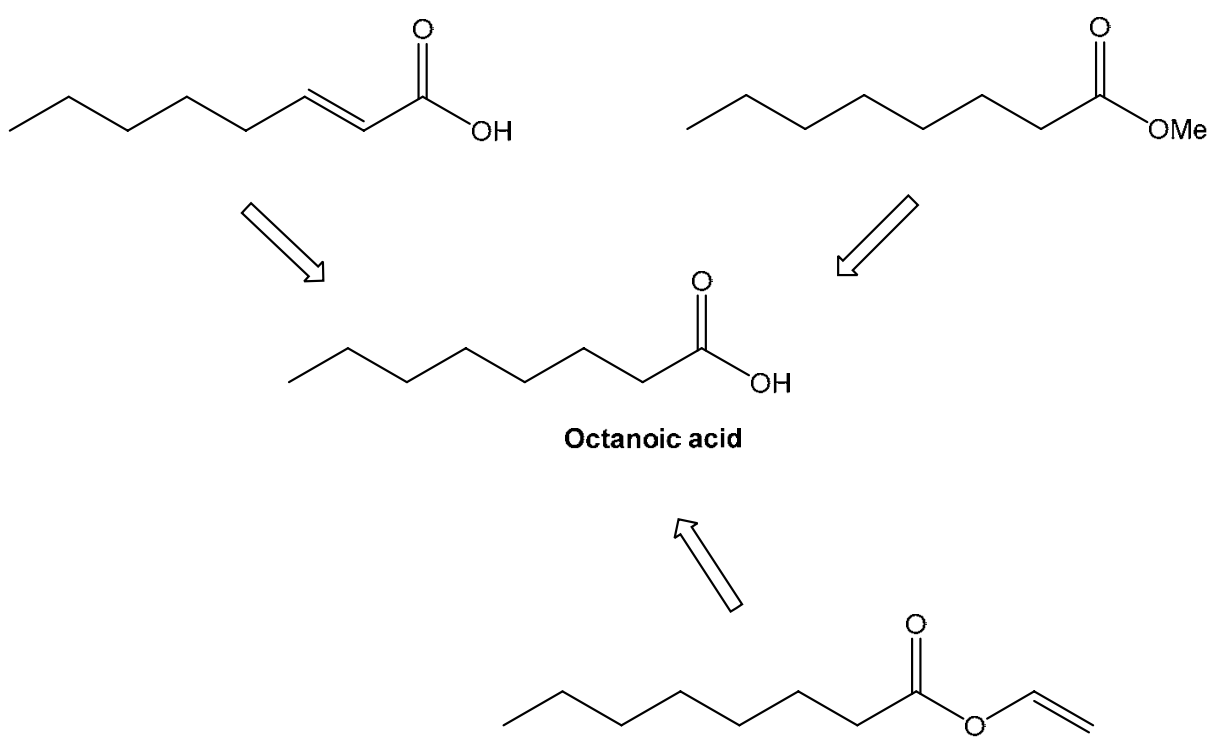

Scheme 3 - Synthetic routes to obtain octanoic acid.<smiles>CCCCC(=CN=CC(CC)CCCC)CC</smiles><smiles>CCCCC(CC)CN</smiles><smiles>CCCCC(CC)CN(CC(CC)CCCC)C(=O)Nc1ccccc1</smiles><smiles>C=C=CCC(CC)C(CCCC)CNCC(CC)CCCC</smiles>

Scheme 4 - Principal methods of synthesis of BEA.

Fatty acids with variable hydrophobic alkyl chain length may act as amphiphiles, in particular the octanoic acid. An interesting application of octanoic acid is its use as co-adsorbent in the preparation of organic dye-sensitized solar cell. The results highlighted that the cell durability was markedly improved with octanoic acid if compared to solar cells without co-adsorbent. ${ }^{80}$

\section{Bis(2-ethylhexyl)amine (BEA)}

The synthetic processes for preparing bis(2ethylhexyl)amine (BEA) are carried out by reacting various amine precursors in variable reaction conditions. The most considerable examples are collected in Scheme $4 .{ }^{81}$

Among the many applications, one of the most recent was the utilization of BEA as extraction agent, at a low cost, to recover indium from an acidic solution containing indium, zinc, lead and tin. ${ }^{82}$ This selective method is really important to separate indium from other metals, used in materials for transparent conductive films, considering its very slight amount principally with respect to zinc and lead.

\section{Complex amphiphiles}

Cryptands, calixarenes, resorcinarenes etc. are some of the most important macroheterocycles studied for their supramolecular functions, considering that the supramolecular structures are the result of linking molecules with intermolecular interactions, like Van der Waals forces, hydrogen bonding etc. ${ }^{83}$

\section{Cryptands}

Cryptands are bicyclic or oligocyclic macroheterocycles appropriately cross-linked with donor atoms correctly positioned in the bridging groups to encapsulate metal ions in cage-like structures. They 
are very potent, selective and strong complexing agents. Cryptands find applications in a wide range of areas of chemistry, biochemistry and material science due to their architectural and functional plasticity. ${ }^{84}$

In general, a number of synthetic procedures have been envelopment for the synthesis of cryptands:

- High dilution technique, that is the most used technique and consists of addition of reactants into a large amount of solvents to form cyclic product by intramolecular reaction and reduce the forming of undesired by-products; ${ }^{85-87}$

- Template synthesis, in which a template organizes the opportune reagents to achieve a particular linking to form the desired compound; ${ }^{88,89}$

- Rigid group principle, method with which macrocycles are formed from acyclic precursors that can rotate about their bonds, lowering their conformational mobility and reducing the possibility of reactive groups coming in proximity. ${ }^{90}$

- Low temperature synthesis, the principle that governs this method is similar to the previous described methodology, taking advantage of the fact that low temperature slows down the movement of the reactive groups, minimizing the polymerization and facilitating macrocyclization. ${ }^{91}$
In particular, cryptand-based amphiphiles are very attractive because of their closed cavity with donor atoms that can be variably placed on the backbone of the macrocycle, allowing a major interaction metal ion/molecular guest.

One of the first examples of cryptand-based amphiphiles synthesis under high dilution conditions achieved substrates with hydrophobic chains of different lengths, performing a series of stable monolayers. (Scheme 5). ${ }^{92,93}$

The synthesized cryptand has been derivatized with acyl chloride of different alkyl chain length. In this manner, the new formed carbonyl groups of the amide portions allow a more compact chain packing without conformational constraints while the phenyl groups help the cavity to obtain rigidity. Amphiphiles and $\mathrm{Cu}(\mathrm{II})$-complexed amphiphiles with variable length chains mixed with selected cryptands, formed stable monolayers at the airwater interface that were filmed on substrates as glass, quartz, fluorite etc. with interesting results. The stability of the monolayers is dramatically dependent upon the lengths of the hydrophobic chains; in fact, it decreases as the chain lengths decreases. $^{94}$ a)<smiles>Cc1ccccc1OCCN1CCN(CCN)CC1</smiles>

b)

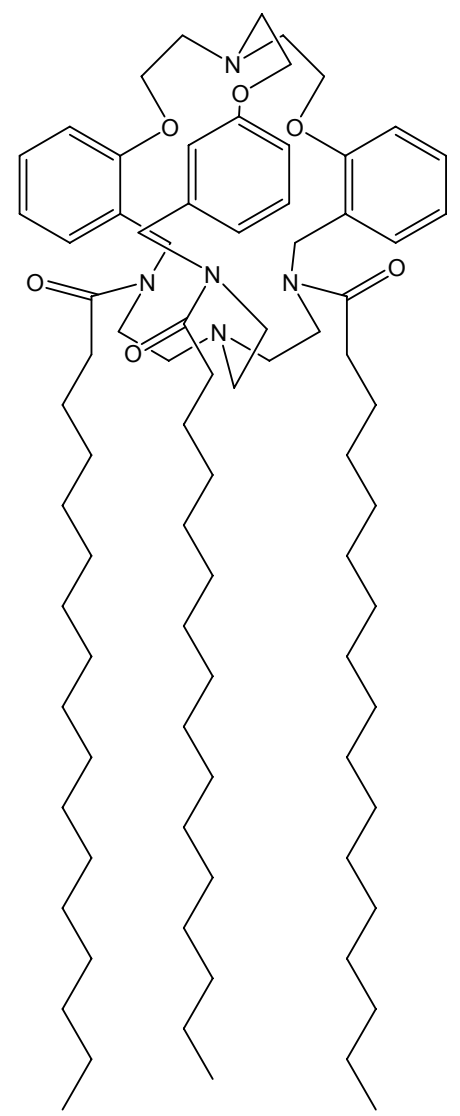

Scheme 5 - a) synthesis of cryptand and cryptand-based amphiphiles b) cryptand-based amphiphile with $\mathrm{C} 15$ length chain. 

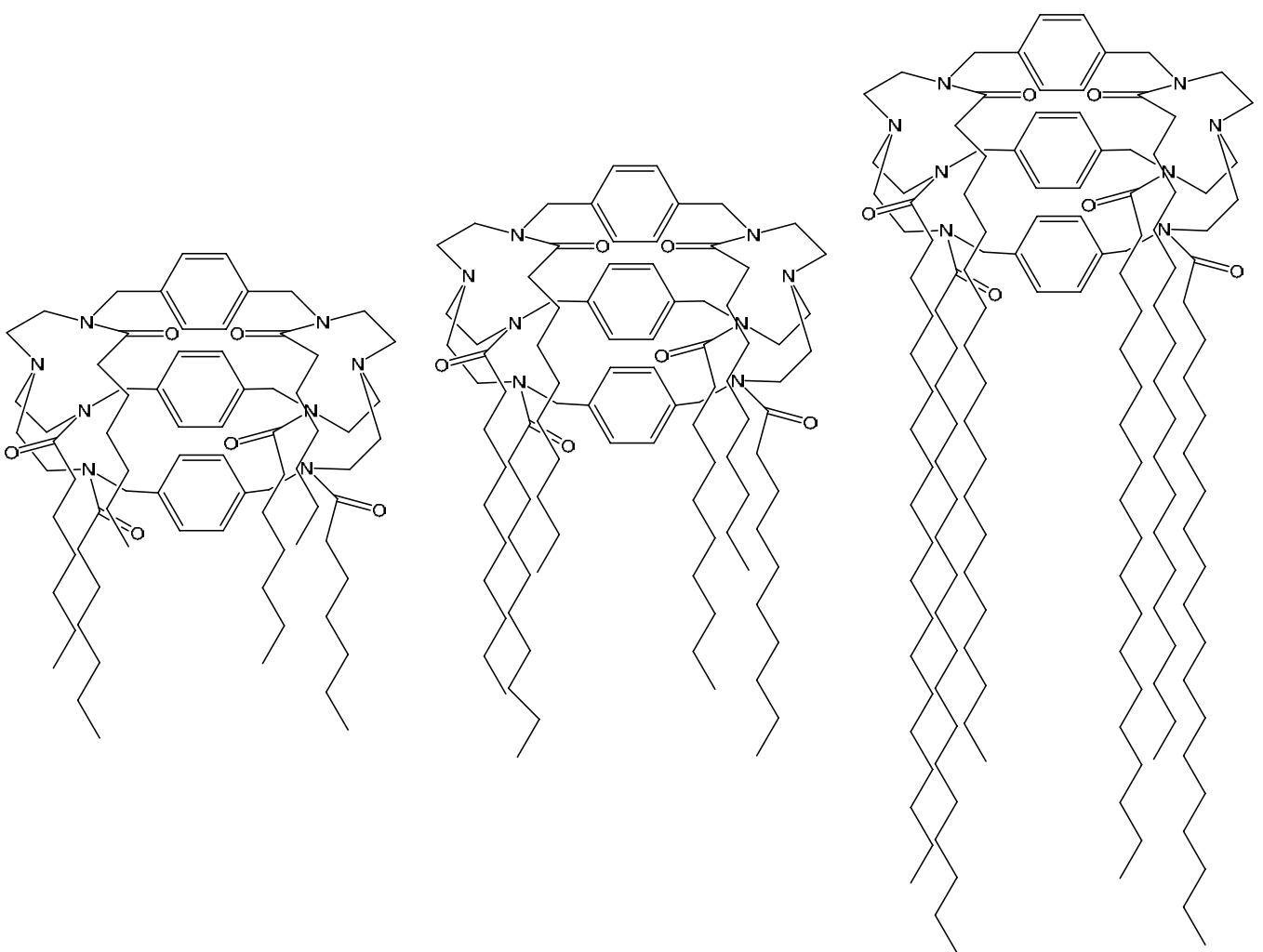

Fig. 3 - Three cryptand based amphiphiles with different chain lengths.

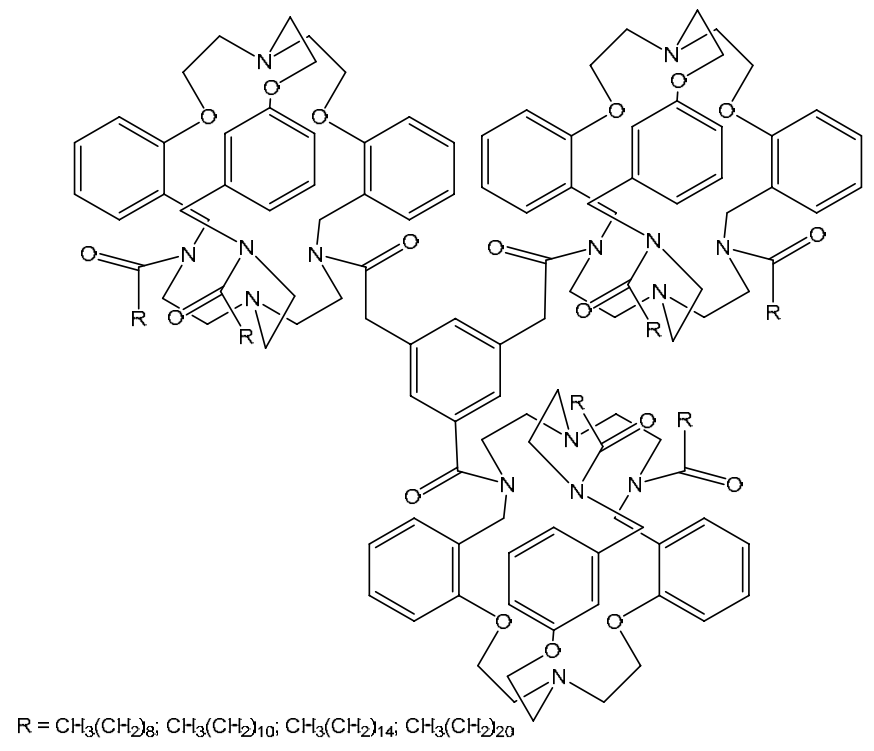

Fig. 4 - Amphiphiles with multi-cryptand headgroups.

A more recent application of this synthetic methodology regards the synthesis of a cryptand headgroup with six secondary amino groups derivatized by different chain lengths to get three cryptand based hexa-tailed neutral amphiphiles (Figure 3). ${ }^{95}$

In particular, the obtained cavity can accommodate two $\mathrm{Cu}$ (II) ions and these copper complexmacrocycles spontaneously agglomerate as giant vesicular microcapsules. The long hydrophobic chain of these macrosystems seems to play an important role to higher encapsulation efficiency.

Amphiphiles with multi-cryptand headgroups were prepared in a multi steps reaction, by using an acyl trichloride as central core (Figure 4). ${ }^{96}$ These amphiphilic macrosystems show an amplified capacity for binding metals and a major stability as giant vesicular microcapsules and monolayers. 


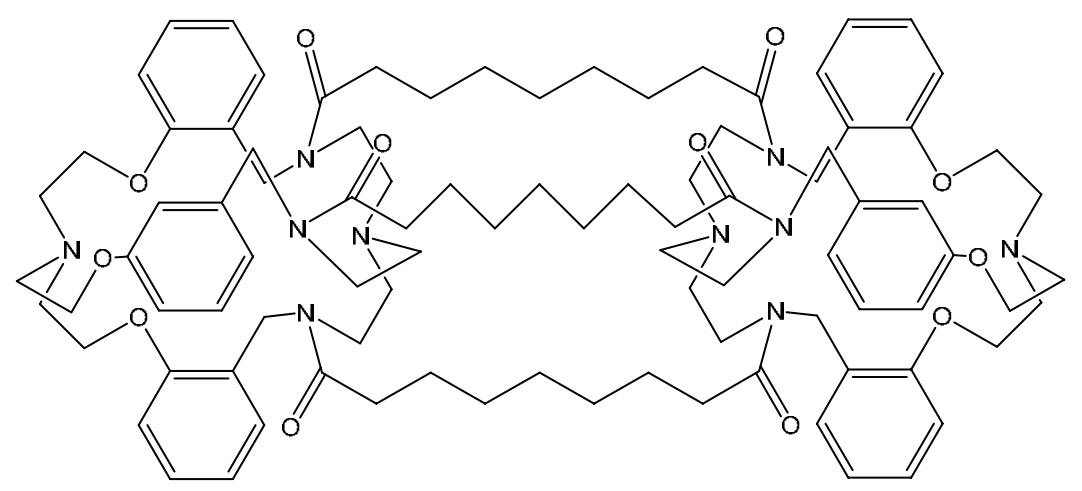

Fig. 5 - Structure of cryptand-based bola-amphiphiles.
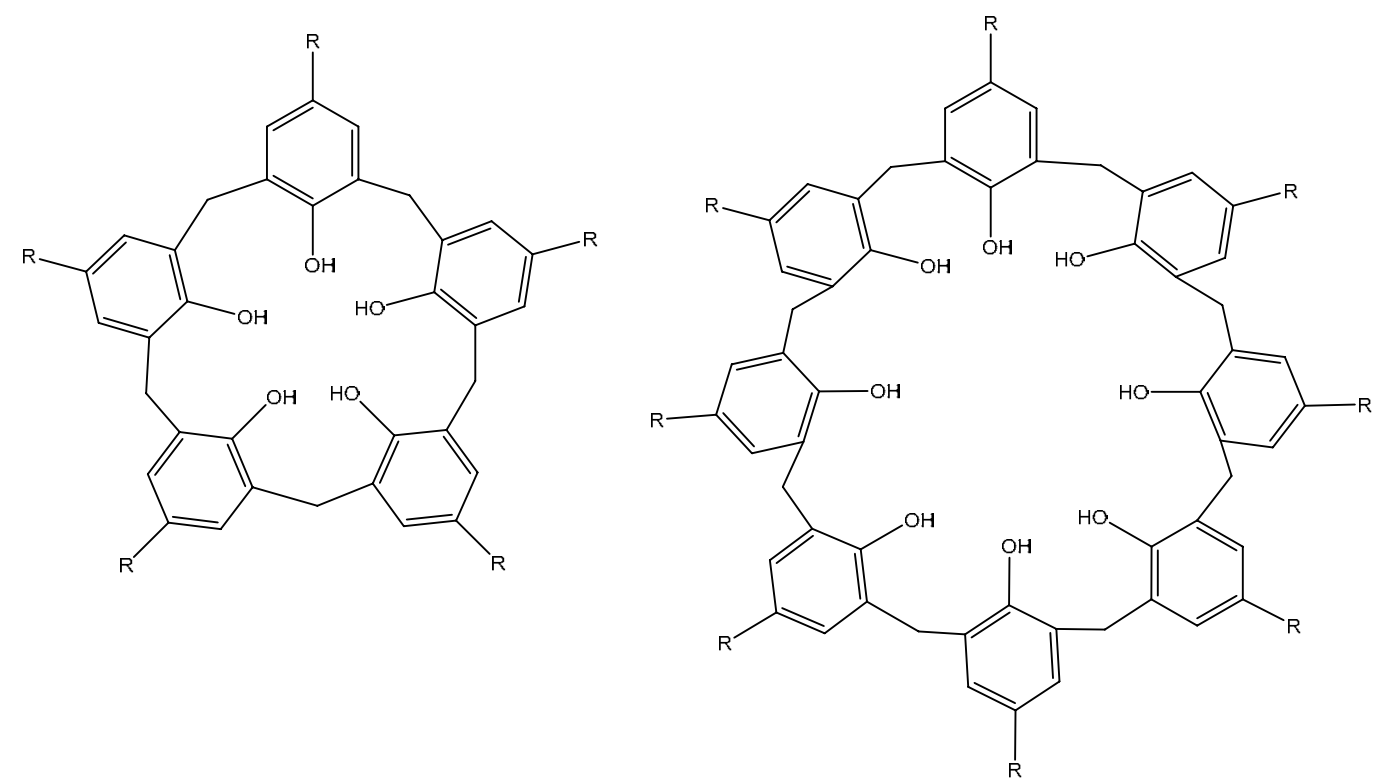

Fig. 6 - Generic structure of calix $[n]$ arenes $(n=5$ and 8$)$.

Cryptand-based bola-amphiphiles are a specific series of surfactants in which two headgroups are conjunct by hydrophobic spacers (Figure 5). ${ }^{97}$

The synthesis was realized by adding an acyl dichloride, as the sebacoyl chloride, to a solution of opportune criptand in tetrahydrofurane as solvent and triethylamine as base, furnishing a spontaneous stable vesicular aggregate. In particular, the length of hydrophobic chain of the derivatizing agent provides the specific dimension of the macrobicyclic cavity to entrap transitionmetal ions as $\mathrm{Cu}(\mathrm{II})$.

\section{Calixarenes and Resorcinarenes}

Calixarenes are macroheterocycles organized like three-dimensional crowns with complexing cavities (Figure 6).

In general, these substrates can be obtained by condensation reactions between phenols and formaldehyde at refluxing in the presence of a strong base. By judicious choice of base, reaction temperature, and reaction time, calixarenes with different ring sizes can be prepared in good yield. Obviously, the cavity dimension can be chemically modified to be selective complexants for a wide range of metal ions..$^{98,99}$

Due to their structure and easy functionalization, calixarenes are ideal molecules for the design of calixarenes-based amphiphiles able to be used as complexants for alkali and alkaline earths, lanthanides and actinides, metal ions such as copper(II), nickel(II), silver(I) and thallium(I), $\mathrm{Zn}(\mathrm{II})$ and $\mathrm{Pd}(\mathrm{II}) .{ }^{100,101}$

Nowadays, great interest is shown in the synthesis of particular derivatives of amphiphilic resorcinarenes, which are calixarene-like macrocyclic supramolecular substrates with resorcinol aromatic rings connected by carbon bridges (Figure 7). ${ }^{102-104}$ 

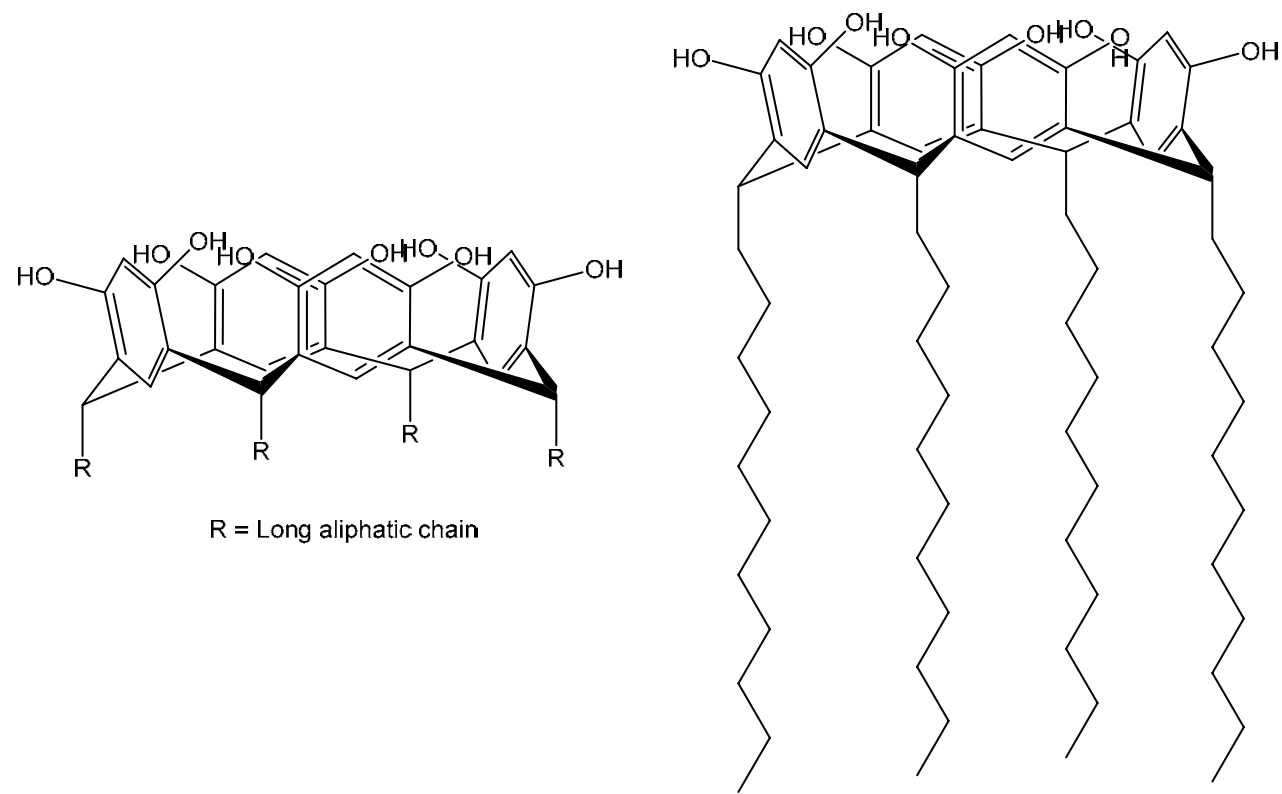

Fig. 7 - Generic structure of amphiphilic resorcinarenes.

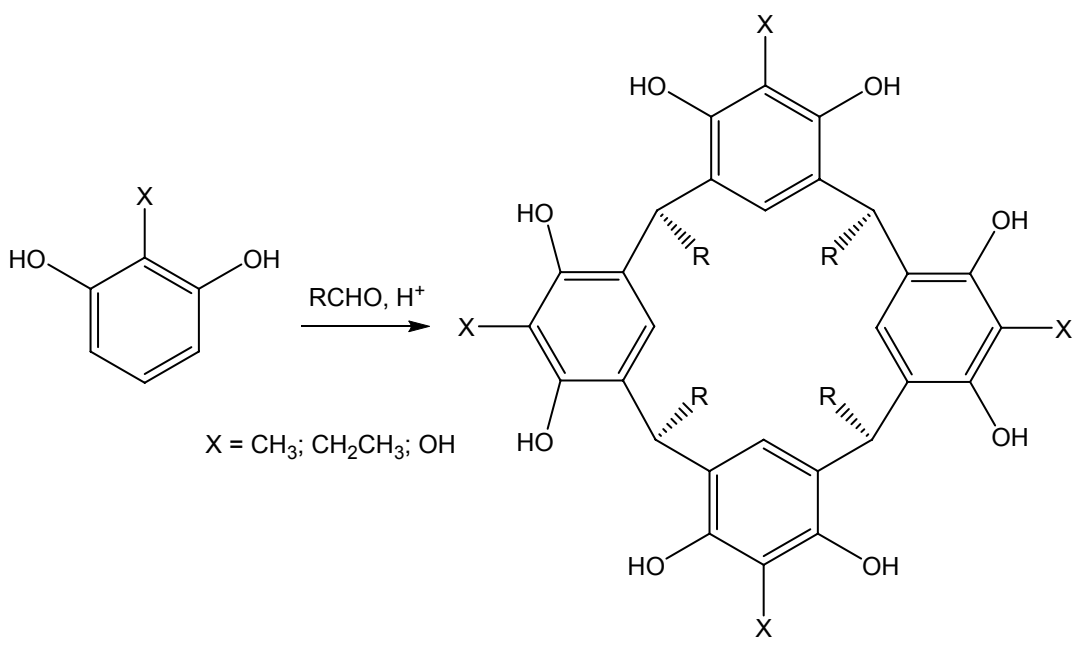

Scheme 6 - The most common synthetic route of amphiphilic resorcinarenes.

The general synthetic procedure of resorcinarenes consists of the acid-catalyzed condensation of resorcinol and aliphatic or aromatic aldehydes (Scheme 6). Amphiphilic resorcinarenes, prepared from long chain aliphatic aldehydes contain a polar and non-polar head within a single molecule. Therefore, their amphiphilic properties can be diversified by the choice of the alkyl chain length or by the addition of polar or ionic groups on the aromatic structure. ${ }^{105,106}$

The concave binding cavity and high affinity towards various guests makes the amphiphilic resorcinarenes as selective binders of cations (alkali and alkaline earth metals, transition metals, ammonium ions), anions and small organic molecules for numerous applications in nanoscience and nanomaterials, biosensors, and biomimetic and biochemical systems. ${ }^{107-112}$

\section{Miscellaneous}

\section{Dendrimers}

Dendrimers are attractive macromolecules whose architecture and properties make them very appropriate for their use in supramolecular assemblies. For example, the complex dendritic structure of G4-48PyP, containing 48 pyridylpropoxy groups (Scheme 7a), was prepared by the use of siloxanetetramer $\left.\left[\left(\mathrm{CH}_{2}=\mathrm{CH}\right) \mathrm{MeSiO}\right)_{4}\right]$ as the core molecule, hydrosilation with $\mathrm{HSiCl}_{3}$ in presence of $\mathrm{Pt} / \mathrm{C}$ and subsequent alcoholysis with allylalcohol (Scheme 7b). Then, G4P-48-Cl dendrimer was terminated with 4-pyridinepropanol. ${ }^{113}$ 
a)

b)

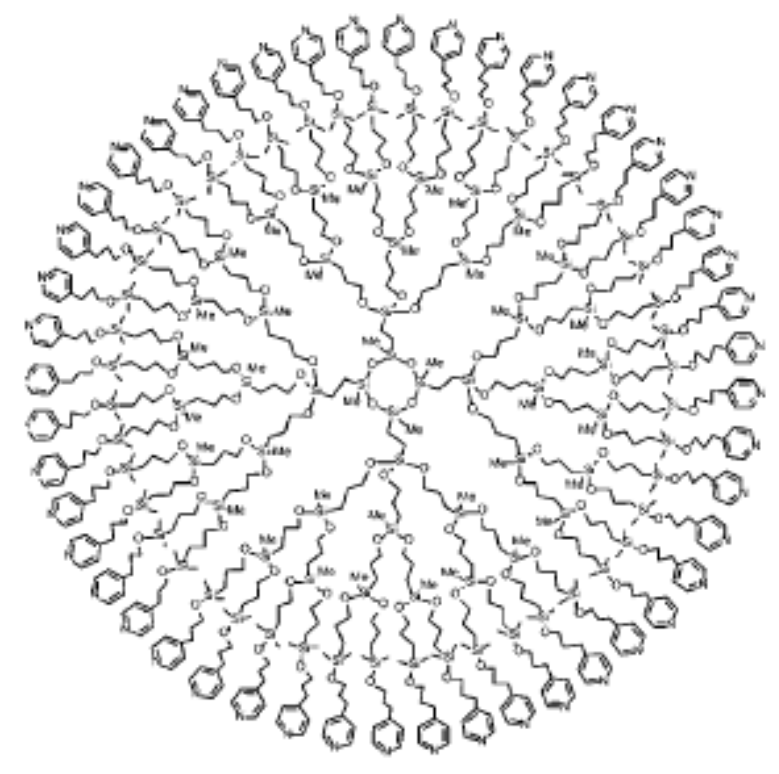

(n)

\begin{tabular}{ll} 
G4-48PyP $\longleftarrow$ 4-pyridinepropanol & $\begin{array}{l}\text { 1) } \mathrm{HSiCl}_{3} \text { Pt/C (for other three twice) } \\
\text { 2)Allylalcohol TMED (for other two twice) }\end{array}$ \\
\hline TMED &
\end{tabular}

Scheme 7 - a) Structure of G4-48PyP; b) synthetic methodology of dendritic amphiphile G4-48PyP.

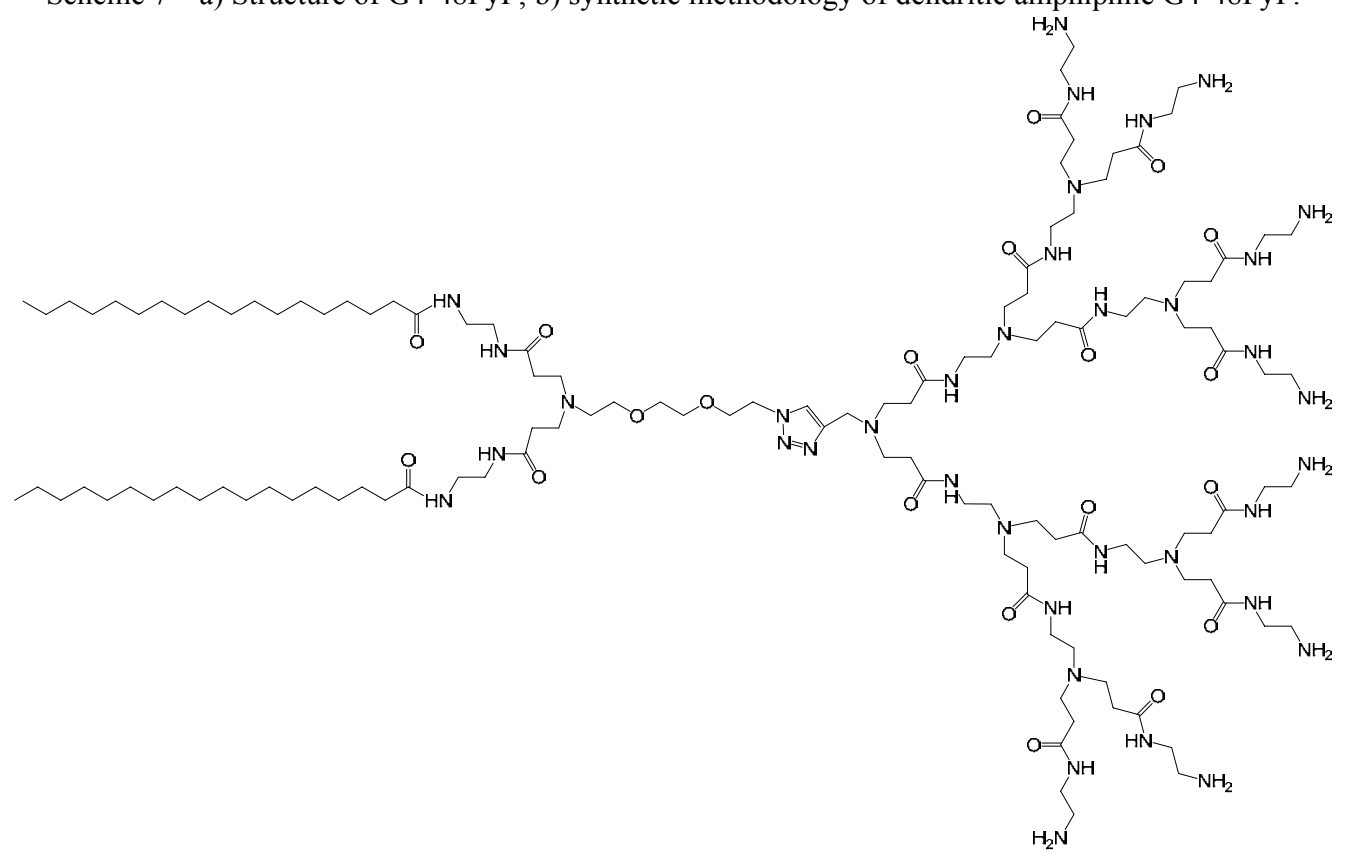

Fig. 8 - Example of amphiphilic dendrimer. 
This dendrimer was prepared as ultra-thin film to form complexes with $\mathrm{Pt}^{2+}$ and $\mathrm{Fe}^{2+}$ ions for a possible their application to molecular-scale electronic devices.

The introduction on the skeletal of dendrimer of a major amphiphilic character amplified from two hydrophobic $\mathrm{C} 18$ alkyl chains brings to obtain spontaneous supramolecular assemblies with unusual and unprecedented properties (Figure 8). ${ }^{114}$

In fact, the contemporary presence of hydrophilic and hydrophobic fragments increases the film stability, which can lead to stable nano-dimensional assemblies for new industrial applications in sensors, optical or biomedical devices. In particular, the increased flexibility of the hydrophobic block and hydrophilicity of polar heads lead to new possibilities for encapsulation of metal ions, larger polar molecules and other catalytic moieties through spherical shaped well-dispersed nanomicelles. More recently, similar amphiphilic dendrimers were synthesized by click coupling of a poly(benzyl ether) block and a poly(ether-ester) block to form a perfect branching structure up to third generation, able to form palladium complexes for application in catalysis or drug delivery. ${ }^{115}$

\section{Amphiphilic siderophore-like}

The siderophores are classic coordination compounds produced by bacteria to acquire metals, especially iron. The amphiphilic siderophore-like span a broad amphiphilic spectrum, which arises from the variations of hydrophobic chain-length (C10-C18) but also because of variations in the hydrophilic head-group, which generally consists of amino acids or peptides. ${ }^{116}$

An interesting example of this amphiphile class is the siderophore reported in figure 9, which in presence of some metals takes on a bismonodentate geometry due to crosslinking of carboxylate groups of amino acids with ions. This complex structure amplifies both its amphiphilic properties because of two long alkyl chain (C16) and the capacity of metal coordination, complexing at the same time various cations such as $\mathrm{Fe}(\mathrm{III})$, $\mathrm{Zn}(\mathrm{II}), \mathrm{Cd}(\mathrm{II})$ and $\mathrm{La}(\mathrm{III}) .{ }^{117}$

Similarly, considering that many polymers, such as the polyvinylpyrrolidone (PVP), have an amphiphilic nature able to capture metals, ${ }^{118,119}$ siderophore-like macromolecules with amphiphile units were prepared from peptides as chelators (i.e. hexahistidine) and oligostyrenes as inductors of high hydrophobicity. ${ }^{120}$ These structural features are the key to assemble peptide polymer amphiphiles into aggregated particles in presence of $\mathrm{Zn}$ (II), $\mathrm{Co}(\mathrm{II}), \mathrm{Cu}(\mathrm{II})$ or micelles with $\mathrm{Ni}(\mathrm{II})$ and $\mathrm{Cd}(\mathrm{II})$ or multilamellar vesicles with $\mathrm{Mn}(\mathrm{II})$. The obtained materials provide a variety of applications as multistimuli-responsive nanomaterials.

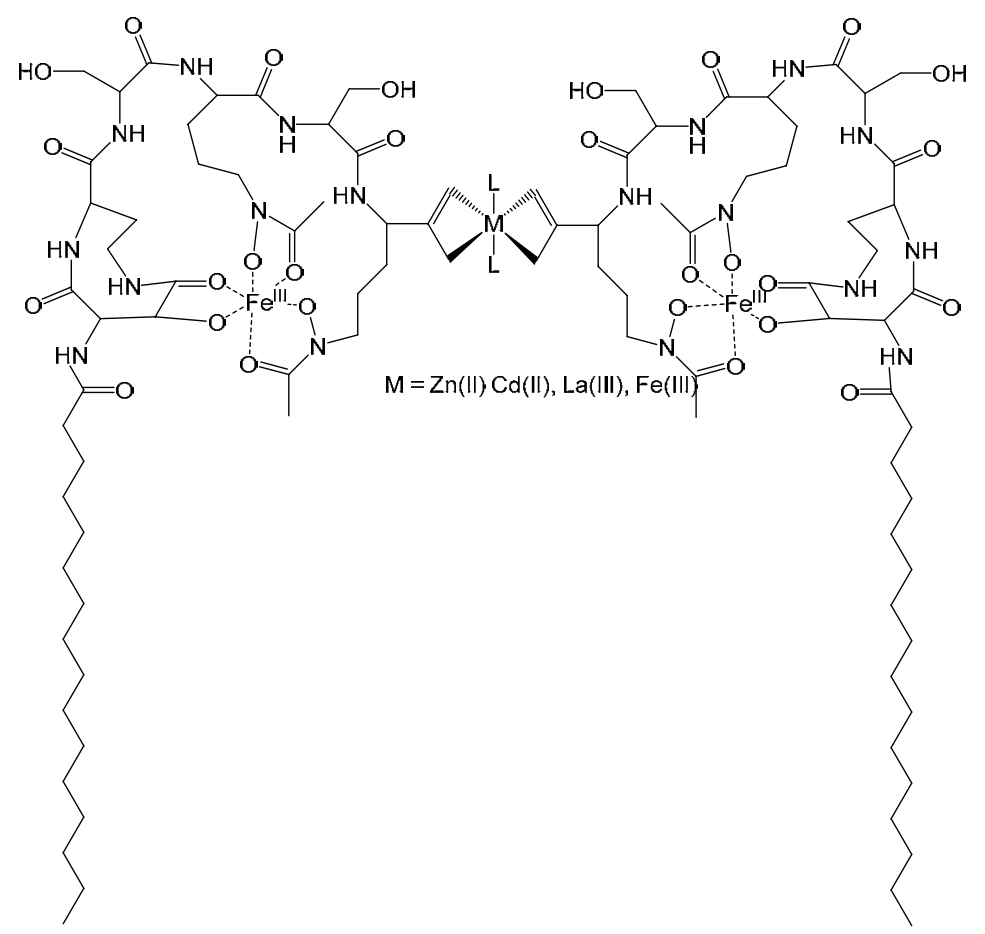

Fig. 9 - An example of amphiphilic siderophore-like, with a hydrophobic C16 chain and peptide as hydrophilic peptide head-group. 
$\Theta_{1}$<smiles></smiles><smiles></smiles>

Fig. 10 - Examples of double-tail lipid-mimic imidazolium-based ionic liquids.

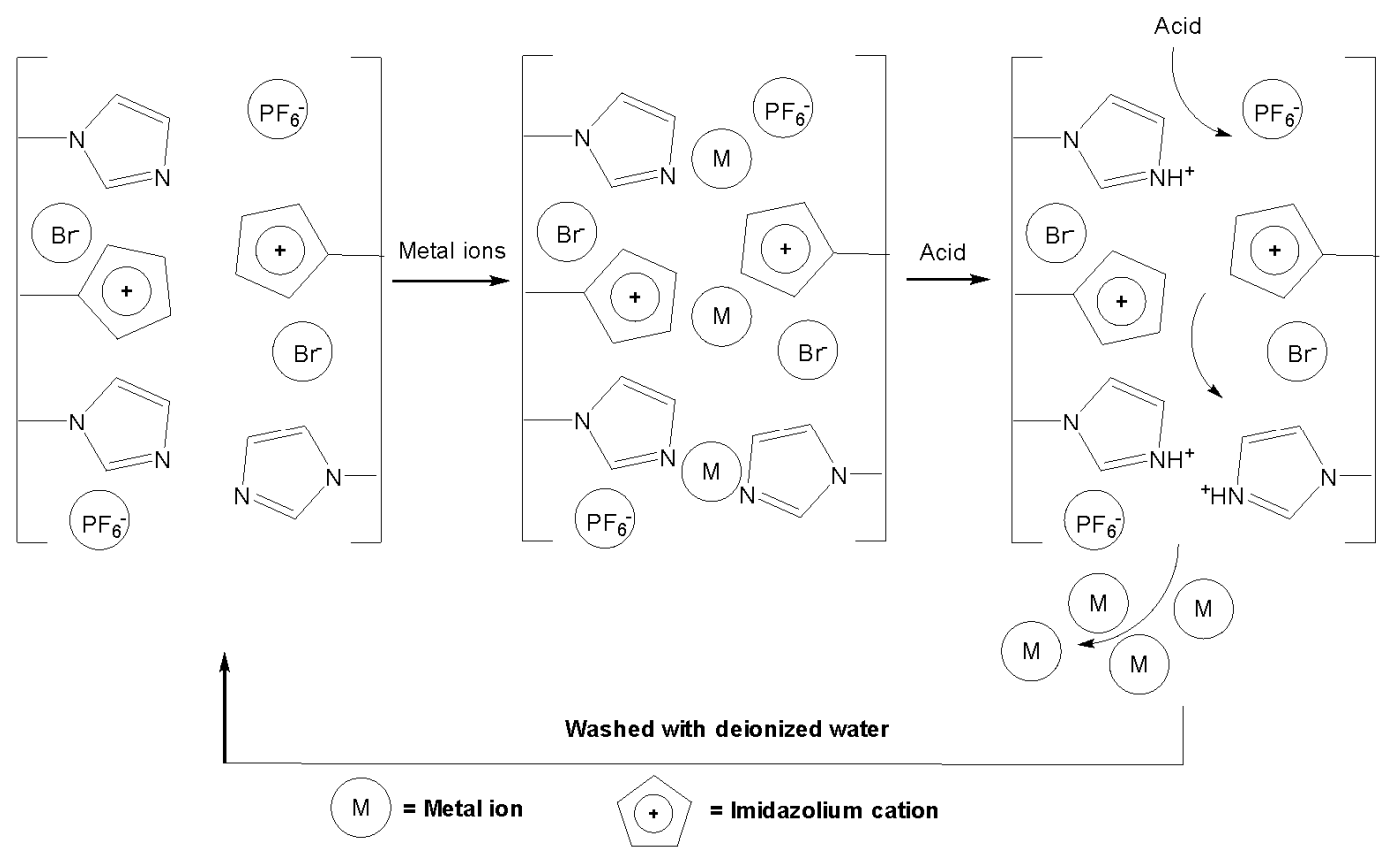

Fig. 11 - Process of absorption and desorption of heavy metal ions by PIL membranes.

\section{Amphiphilic ionic liquids}

Ionic liquids (ILs) are a class of organic salts whose melting temperature falls below the conventional limit of $100^{\circ} \mathrm{C}$. Nowadays, due to their low vapor pressure and other peculiar characteristics, they are widely employed in organic synthesis as solvents so-called green, ${ }^{121-124}$ but also used for other applications, such as industrial, pharmacology, bio-medicine, nanotechnology, etc. ${ }^{125-127}$

Generally, amphiphilic ionic liquids are structures with a small hydrophilic head, generally represented by an imidazolium cation, and one or more hydrophobic moieties present on the backbone of the heterocycle. An example of double-tail lipid-mimic imidazolium-based ionic liquids is illustrated in Figure 10. ${ }^{128}$
Really, these structures show great similarity with phospholipids and for this reason, they are prevalently employed as phospholipid-mimics in bio-medicine field.

A particular class of ILs are the so-called ionic liquid crystals (ILCs), that add the properties of liquid crystals (self-healing, order and mobility) to the final material. ${ }^{129}$ The introduction of a metal center in the ILCs structure, yield the so-called metallomesogens considered multifunctional materials that can add properties like luminescence or redox activity making them attractive multifunctional materials for practical applications. ${ }^{130}$

On the other hand, poly(ionic liquid) (PILs) are particular amphyphylic polymer membranes with porous of variable dimensions and exhibit high 
absorption capacity of heavy metal ions (including $\mathrm{Hg}^{2+}, \mathrm{Pb}^{2+}, \mathrm{Cu}^{2+}, \mathrm{Cd}^{2+}$, and $\left.\mathrm{Zn}^{2+}\right) .{ }^{131}$ The PILs were synthesized via copolymerization (and photocrosslinking) of vinyl imidazole with imidazolium type IL monomers, using poly(ethylene glycol) diacrylate (PEGDA) as a crosslinking agent. The porous structures formed inside these membranes can be adjusted by the molar ratio of hydrophilic and hydrophobic segments, and, therefore, they are able to capture metals of various size, increasing ion absorption capacity. Moreover, the most ingenious property of these polymer membranes is that they can be easily recycled without significant decrease of activity trough a simple desorption process after treatment with acids and deionized water (Figure 11).

\section{Supramolecular aggregates of luminescent transition metal complexes in water}

Scientists try harder and harder to inspire from nature in many domains, from energy applications ${ }^{132,133}$ catalysis $^{134,135}$ to the fabrication of nanobiomaterials ${ }^{136,137}$ and so on. Water is used more and more in chemistry because of its importance in sustaining life, controlling many processes in nature and because of its green properties.

Micellar water solutions of amphiphiles are important from technological point of view, due to their ability to solubilize hydrophobic molecules, property frequently used not only in detergency, but also in pharmaceutical formulations of water insoluble drugs, incorporation of dyes and fragrance products in cosmetics. ${ }^{1}$ Transition metal complexes are mainly hydrophobic. Opportune engineering of the molecular skeleton can yield solubility in water by graphing hydrophilic groups on the ligands or introducing solubilising counterions, however as far as the photophysical properties are concerned, often in the solution the complexes suffer from quenching of luminescence due to vibrational motions, presence of oxygen, etc. ${ }^{138}$ A winning strategy may be the assembly of complexes into supramolecular structures in water that decreases the motion, increases the rigidity and may keep apart the complex cations, avoiding the so-called aggregation induced quenching detrimental for luminescence.

In this paragraph different strategies to obtain supramolecular luminescent systems with transition metal complexes in water will be reviewed. Mainly it will focus on the insertion of transition metal complexes into micelles formed by classical surfactants in water or opportune functionalization to obtain metallosurfactants able to form "pure" supramolecular structures in water. Although the focus will be on low molecular systems, also some polymeric representative examples will be presented.

Figure 12 shows a schematic illustration of different supramolecular micelles formed in water with low molecular weight transition metal centers and their positioning as a function of their nature, molecular structure and species involved.

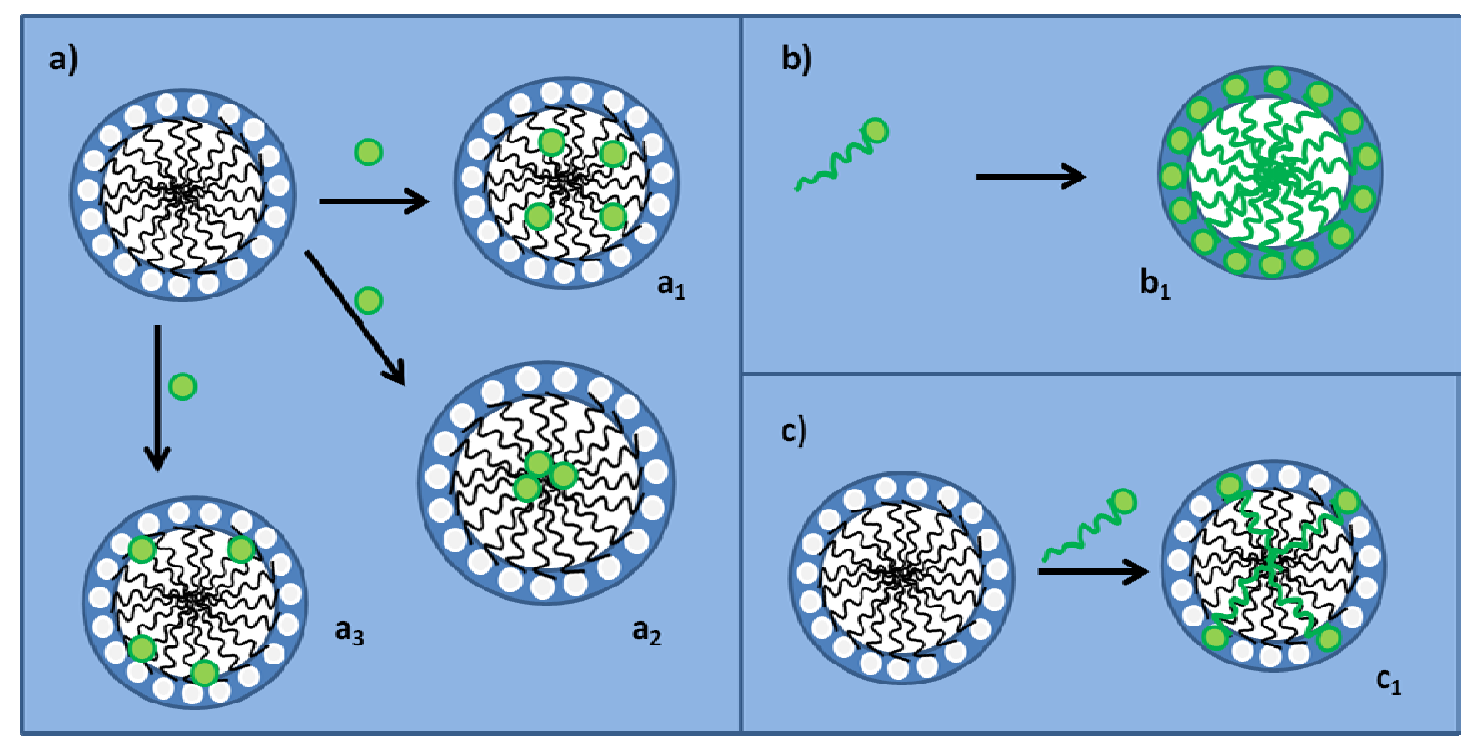

Fig. 12 - Schematic illustration showing different types of functional micelles with the position of the transition metal complex as a function of its nature and structure: a) insertion of non amphiphilic transition metal complex into micellar structures of classical surfactants, b) metallosurfactants forming micellar structures, c) amphiphilic transition metal complex co-assembled with surfactants. 
The insertion of the complex into the micellar solution of classical surfactants may increase the rigidity and protect the complex from the environment. The positioning of the complex in the micelles depends mainly on its nature, and thus can be situated in the hydrophobic or hydrophilic part of the micelle (Figure 1). ${ }^{139}$ This strategy however was showed that cannot overcome totally the aggregation phenomena of the complexes inside the micelles, detrimental for luminescence properties.

Covalently linking the ligands to hydrophobic alkyl chains may confer the required amphiphilicity for self-assembling hydrophilic complexes into micellar structures in water yielding thus metallosurfactants ${ }^{140}$ (Figure 1b). A greater miscibility and better dispersion can be however obtained with a "mixt" strategy consisting in the use of metallosurfactants co-assembled with the classical surfactants (Figure 1c).

As mentioned before, metallosurfactants are made up of two chemically distinct parts: the hydrophobic part consists in long hydrophobic alkyl chains grafted on one of the ligands and the hydrophilic head group that usually contains the transition metal opportunely functionalized. However, as a function of its nature and the nature of the coordinated ligands, the transition metal complex ion can also form the hydrophobic part of the molecule when on the ligands are grafted hydrophilic substituents. ${ }^{141}$

With increasing concentration, some metallosurfactants may organize into ordered lyotropic supramolecular structures in water (metallomesogens). ${ }^{140}$ Introducing lyotropic properties in water with transition metal complexes is not an easy task, the often bulky coordination geometry of the metal center causing a delicate balance between the metal containing hydrophilic head group and hydrophobic alkyl chains. Therefore, beside of some simple structure metal salts of dodecylbenzenesulfonic acid organizing into lamellar mesophases in water ${ }^{142}$ only few examples of high coordination transition number lyotropic surfactants were reported up-to-date.

Obtaining complex dynamic supramolecular systems in water with transition metals is of interest both from scientific and applicative point of view. The redox, catalytic, magnetic and optical properties of the metal center are usually sensitive to the molecular surroundings and dynamics and the final properties of the system are not usually a sum of the properties of the different molecular parts but new and synergistic properties can be obtained. Accurate photophysical investigations on single component and on the aggregates may be used as a tool to understand the self-assembling mechanism $^{141,143}$ and comparison with results obtained in the condensed state where determination of the structure is relatively more easy, may give information's on the molecular environment around the complex cation and eventually explain the supramolecular dynamic organization in water.

The coordination geometry requirements of the metal center generate intricate supramolecular architectures also additional non-covalent interactions (electrostatic, weak metal-metal and metal-ligand intermolecular interactions) that cannot be obtained in purely organic counterparts. ${ }^{144}$ Thus, although the shape of the aggregates with small molecular weight organic surfactants was shown to be quite easily predicted by two models (one based on the interfacial curvature of an amphiphilic film at an interface and another based on the critical packing parameter of the amphiphilic molecule itself), ${ }^{1}$ with transition metal complexes the increased complexity from one side and the less data on the other side makes the prediction difficult. ${ }^{145}$ Moreover, the complexity results in more intricate structures, like complex shape micellar, ${ }^{146}$ wormlike aggregates, ${ }^{147}$ vesicular multilayered spheres, ${ }^{148}$ nano-rods and nano-fibres $^{149}$ or other bi- and tri-dimensional structures. However, the unique dynamic structures with modulable properties derived from the metal center are considered a winning strategy in several applications areas, although yet beside the synthesis of some functional mesoporous materials for organic light-emitting diodes or catalysis, the systems were only studied for their magnetic, electric, optical and photophysical properties.

\section{Platinum(II)}

The square planar geometry of Pt(II) favor the tendency to aggregation into supramolecular structures, the distance between the metal centers being controlled by the rational functionalization of the ligands in the coordination sphere, controlling the luminescence efficiency and the color tuning. ${ }^{149}$ L. De Cola et co. reported the synthesis of a series of neutral Pt(II) complexes based on a terdentate dianionic ligand and functionalized ancillary monodentate pyridinic ligand with hydrophilic units (Figure 13). ${ }^{150,151}$ 
<smiles>FC(F)(F)C(F)(F)F</smiles>

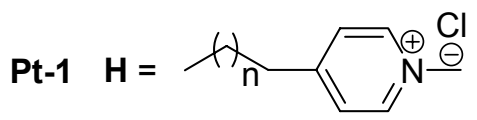

Pt-2

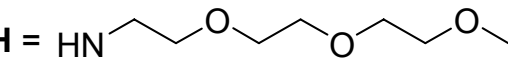

Fig. 13 - Chemical structure of amphiphilic Pt(II) complexes.<smiles></smiles>

Neutral cyclometallated Ir(III) complexes<smiles>[R5]N=CN(CCOCCOC)CCOCCOCCOC</smiles>

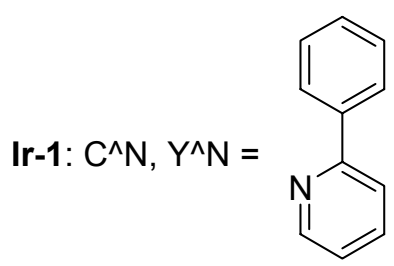<smiles>C[C@@H](CCOc1ccccc1C(=O)O)N=[W]</smiles>

Fig. 14 - Chemical structures of neutral Ir(III) coordination complexes.

The complexes showed a strong ability to aggregate into supramolecular aggregates in water, forming spherical micelles with the hydrophilic units at the periphery and the hydrophobic Pt(II) complex in the center of the micelles. While in the case of the alkyl ionic pyrimidinium substituent (Pt-1) a quenching effect was observed attributed quite to the proximity of the pyrimidinium units, in the case of functionalization of the co-ligand with hydrophylic triethylene glycol chains, a close contact between the $\mathrm{Pt}(\mathrm{II})$ complexes in the center of the micelles favored $\mathrm{Pt} \cdots \mathrm{Pt}$ metallophilic interactions. Hence, the micellar solutions of Pt-2 and Pt-3 showed considerably higher emission efficiencies $(72 \%)$ with respect to the monomeric specie in DCM (1\%).

\section{Iridium(III)}

Despite the bulkiness of octahedral cyclometallated $\operatorname{Ir}(\mathrm{III})$ complexes that does not easily permit the arrangement into ordered structures, their excellent photophysical properties and sensitivity to the molecular environment prompted several groups to use them to build supramolecular systems in aqueous media both by inserting it into micellar solutions of common surfactants or by functionalisation of one of the ligands to induce amphiphilicity in the molecular structure. Beside the strong research interest for practical applications in biomedical fields, the systems were also used attempting to obtain highly luminescent and mechanically stable mesoporous silica materials with improved photostability.

The chemistry of $\operatorname{Ir}(\mathrm{III})$ cyclometallated complexes permits the synthesis of a large variety of neutral or ionic species with amphipilic, hydrophilic or hydrophobic character. In figure 14 and 15 are represented the chemical structures of Ir(III) coordination complexes that were the subject of luminescence studies on supramolecular systems in water and will be discussed further.

Micellar solutions of common surfactants cationic cetyltrimethyl ammonium bromide (CTAB) and neutral polymeric triblock copolymer poly(ethylene glycol)-block-poly(propylene glycol)-block-poly(ethylene glycol) (P123) respectively, containing a non-amphiphilic neutral Ir(III) cyclometallated complex (Ir-1) were used as functional templates for obtaining luminescent mesoporous materials. Ethanol was employed as co-solvent. The authors claimed after accurate structural and photophysical investigations that 
complex Ir-1 preferred an hydrophobic environment, but while in the case of CTAB system it arranges preferentially between the hydrophobic tails (Figure 1a - case a1), in the polymeric system is located in the centre of micelle cores causing an enlargement of micelle dimensions (Figure 1a-case a1). ${ }^{139}$ The obtained hybrid materials showed the characteristic emission of Ir-1 complex, however quenching was observed specially when the polymeric surfactant was used as template.

Vesicular supramolecular aggregates in water were obtained by Mauro et al. by functionalization of a neutral $\operatorname{Ir}(\mathrm{III})$ cyclometallated complex (complex Ir-2 in Figure 14) having an ancillary picolinate ligand substituted with a tail terminated with a negatively charged sulphate group. ${ }^{141}$ The complexes are segregated in bilayers, exposing the anionic groups to the aqueous environment, being protected against water and dioxygen molecules, well-known for their quenching effects. Thus, the vesicular systems show a considerable blue shift of the emission maxima with respect to the monomeric species and life-times comparable with the life-times of the monomeric species in degassed solution.

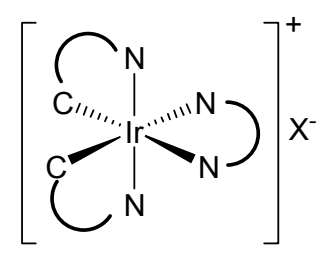

Ionic cyclometallated $\operatorname{Ir}(\mathrm{III})$ complexes

Ir-3: $\mathrm{C}^{\wedge} \mathrm{N}=$<smiles></smiles><smiles>N#C[AlH2]</smiles><smiles>S=C([I-])N=[W]</smiles><smiles>c1ccccc1</smiles>

Monocationic Ir(III) amphiphilic complex Ir-3 (Figure 15) was used in a co-assembly method with micellar solution of CTAB in water/EtOH for the synthesis of mesoporous highly luminescent materials. ${ }^{152}$ Spherical micelles were formed with the Ir-surfactant being part of the micellar structure, inserted in-between the CTAB surfactants which assured a better dispersion than in the case of Ir-1 (Figure 12c - case c). This resulted in considerably longer life-times and excellent luminescence quantum yields for the final functional nanocomposite materials.

The sensitivity of the $\operatorname{Ir}(\mathrm{III})$ cyclometallated complexes to the molecular environment may be a tool to probe the position of the complex inside the micellar systems substantiated with other spectral and rheological methods. This was demonstrated by Talarico et al. with two cationic Ir(III) complexes, an amphiphilic specie bearing a multicatenar ancillary bipyridine-based ligand (Ir-4 in Figure $15)^{153}$ and respectively a hydrophilic specie (Ir-5 in Figure 15) ${ }^{154}$. The complexes were inserted into the micellar and cubic phases formed by the polymeric surfactant Pluronic F127 [poly(ethylene oxide) ${ }_{100^{-}}$

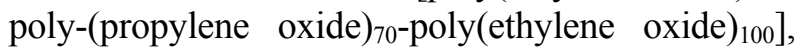
used as structure directing agent for the synthesis of mesoporous SBA-16 systems.

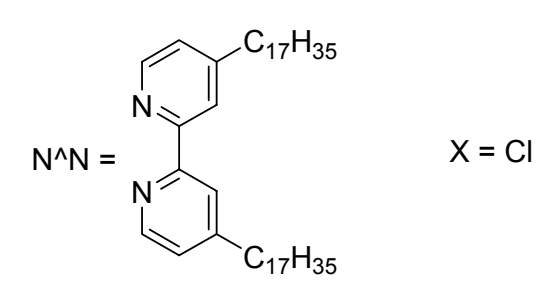

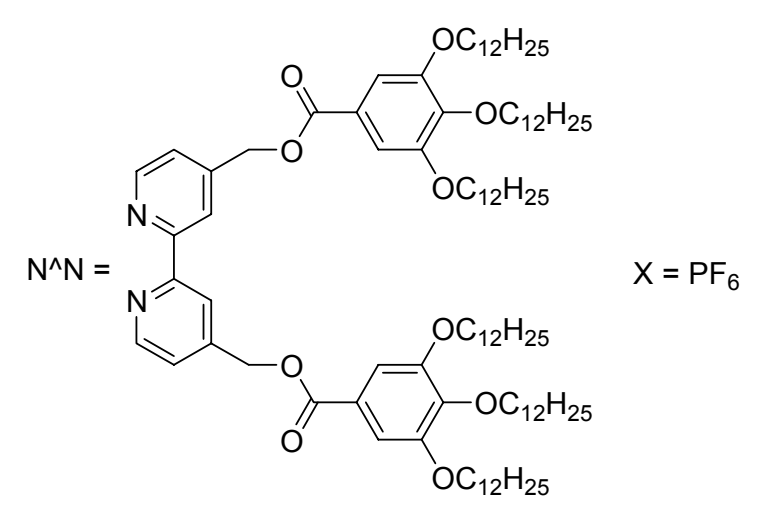<smiles>[X]=[W]=[N-]</smiles>

Fig. 15 - Chemical structures of ionic Ir(III) coordination complexes. 
The amphiphilic complex Ir-4 showed poor solubility in water media, so THF was used as cosolvent. The monomeric specie in THF solution emitted in the orange-red region of the visible spectrum, with a luminescence quantum yield of 4.5\%. However, despite its amphiphilic structure, only small aggregates were detected in water media, that showed a blue-shift of the emission maxima and increased 5-fold the luminescence quantum yield with respect to the monomeric solvated specie. Similar photophysical properties showed also the system formed by F127 surfactant and Ir(III) complex in water. In both micellar and cubic phase, the complex at low concentration is situated inside the hydrophobic apolar core, but with increasing concentration a progressive displacement towards the corona polar region was observed.

By changing in the nature of the $\operatorname{Ir}(\mathrm{III})$ complex, using a hydrophilic cationic complex (Ir5 in Figure 15), a good dispersion of the chromophore in the corona region of the micelles forming the micellar and cubic dynamic system of the F127 polymeric surfactant in water was obtained. ${ }^{154}$

\section{Ruthenium(II)}

Stable multilayered micelles were obtained with amphiphilic bipyridine-based $\mathrm{Ru}(\mathrm{II})$ dianionic complexes presented in Figure $16 .{ }^{148}$ The luminescence of the monomeric form of the complex was totally quenched in solution, but strong emission upon aggregation was obtained for the multilayered micelles. The emission efficiency depended on the aggregates size and type, and it was shown to be mainly due to increase of the rigidity of the system. Moreover, the presence of the hexafluorophosphate counterions was essential for the self-assembling, since with chlorine counterion no supramolecular structures were formed.

\section{Rhenium(I)}

An amphiphilic neutral dinuclear Re(I) complex bearing a dendritic ligand functionalized with three glycosylated units (Figure 17) was investigated as luminescent probe for cell imaging. ${ }^{155}$ The photophysical properties were studied in aqueous solution where the authors claimed that it organizes into direct micellar structures with the metallic head oriented internally forming the hydrophobic region. Consequently, the complex shows a weak emission in the yellow-orange region of the visible spectrum with low quantum efficiencies due to quenching processes and aggregation phenomena.<smiles>[Z20]CNC1(NCC)NCCN1</smiles><smiles></smiles><smiles>[Y]=[P+]=P</smiles>

Fig. 16 - Chemical structure of amphiphilic Ru(II) complex.

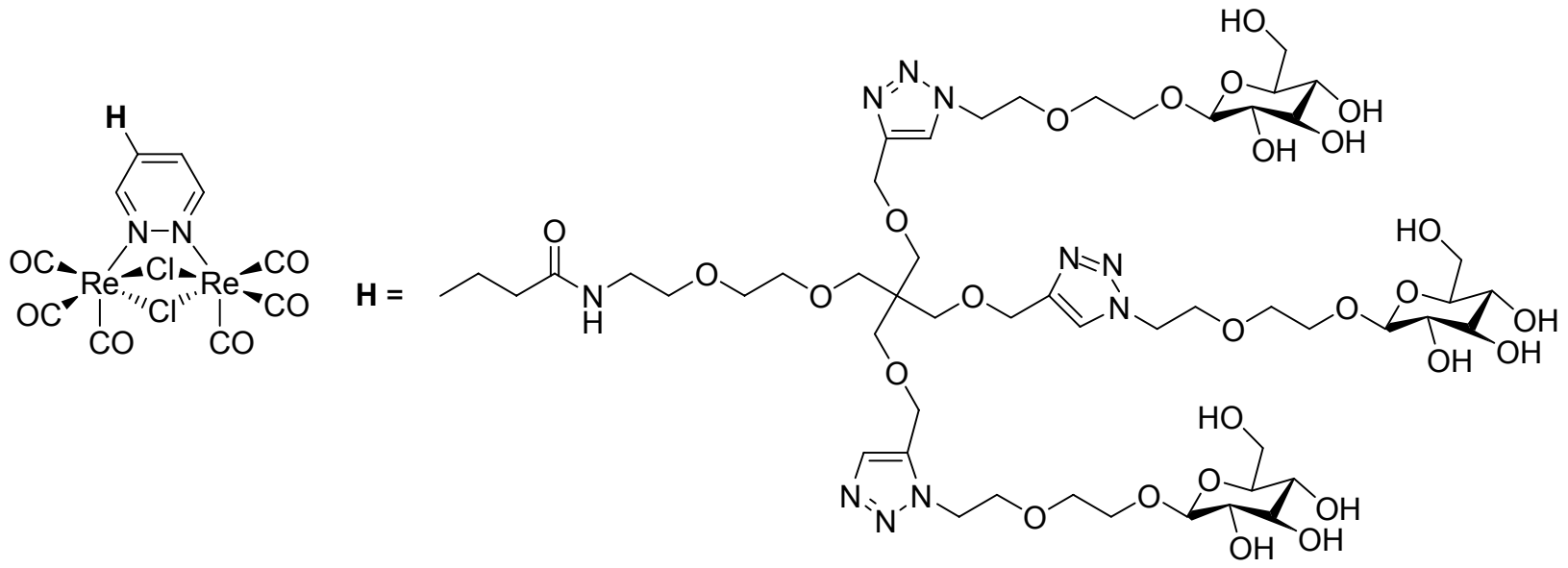

Fig. 17 - Chemical structure of amphiphilic Rh(I) complex. 

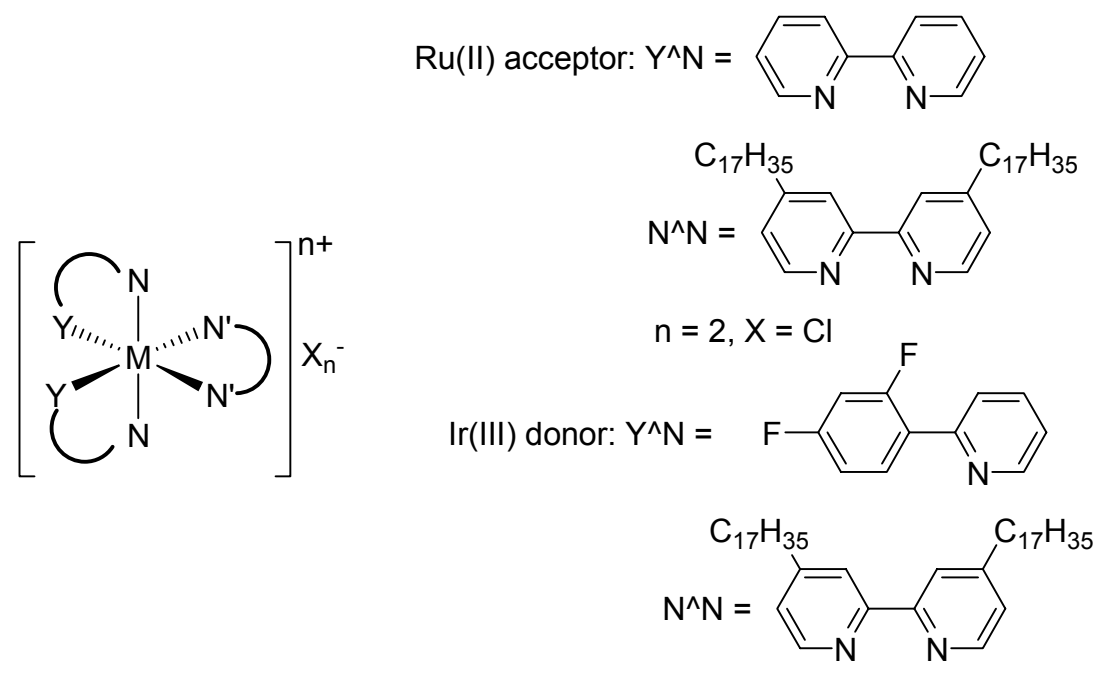

$\mathrm{n}=1, \mathrm{X}=\mathrm{Cl}$

Fig. 18 - Chemical structure of amphiphilic Ru(II) acceptor and Ir(III) donor complexes.

\section{Mixed micelles}

Mixed bimetallic micelles with efficient electronic energy-transfer processes were obtained with metallosurfactants based on an energy acceptor $\mathrm{Ru}(\mathrm{II})$ and an energy donor $\operatorname{Ir}(\mathrm{II})$ amphiphiles (Figure 18). The tunability of the electron transfer processes was improved by adding a third "innocent" component (CTAB) surfactant. ${ }^{156}$ The simple monometallic micelles displayed photophysical properties similar to their non-functionalized parental species (in the red region for the $\mathrm{Ru}(\mathrm{II})$ complex and a green emission for the $\operatorname{Ir}(\mathrm{III})$ compound) with biexponential lifetime profiles and enhanced emission quantum yields with respect to the monomeric species due to the reduction of the vibrational modes.

\section{CONCLUSIONS}

Specifically chosen amphiphiles can act as building blocks to form novel structures with new functions and properties. This aspect can be strengthened if metal atoms are included. This philosophy allows to reach higher levels of complexity with respect to those already obtained in amphiphile-based materials. This gives addedvalue materials so novel methodologies are currently being developed to accomplish this task. These potentialities are even more effective if molecular architecture can be manipulated by synthetic chemistry, allowing to obtain a virtually unlimited scenario of possible molecules and consequently novel properties. The state of the art has been presented and forefront technologies have been introduced.

The possibility to control the complexity in the nanoworld would make real the building up of "artificial" systems that could improve the human life by realizing novel complex materials/ systems/devices amplifying the range of their capabilities in every desired field. We hope that with our contribution we have made the reader curious to this exciting aspect furnishing, at the same time, useful information for new research.

Acknowledgements. P. C. and D. L. wish to thank Prof. Vincenzo Turco Liveri, retired Professor of the University of Palermo (Italy). The huge work he has carried out in the field of amphiphiles during his brilliant career allowed us to critically learn and understand a lot about amphiphiles selfassembly and dynamics. E. I. S. acknowledges the support of the Romanian Academy, Project 4.1. The authors also acknowledge the support from the Romanian Academy and from the CNR-RA bilateral project 2020-2022 (prot. N. 0088276 from 19/12/2019).

\section{REFERENCES}

1. M. Ramanathan, L. K. Shrestha, T. Mori, Q. Ji, J. P. Hill and K. Ariga, Phys. Chem. Chem. Phys., 2013, 15, 10580 .

2. D. Lombardo, P. Calandra, D. Barreca, S. Magazù and M. A. Kiselev, Nanomaterials 2016, 6, 125, 26.

3. D. Lombardo, M. Kiselev and P. Calandra, Adv. Cond. Matter Phys., 2015, Article ID 151683, 22 pp.

4. I. Hamley, "Introduction to Soft Matter", J. Wiley, Chichester, 2000.

5. H. Hu, M. Gopinadhan and C. O. Osuji, Soft Matter., 2014, 10, 3867.

6. M. Shimomura and T. Sawadaishi, Curr. Op. Coll. Interface Sci., 2001, 6, 11. 
7. R. A. L. Jones, Eur. J. Phys. 2002, 23, 652.

8. R. Backov, Soft Matter 2006, 2, 452.

9. J. N. Israelachvili, "Intermolecular and Surface Forces", Academic Press, 2010.

10. J. M. Guevara-Vela, E. Romero-Montalvo, V. A. Mora Gómez, R. Chávez-Calvillo, M. García-Revilla, E. Francisco, Á. M. Pendása and T. Rocha-Rinza, Phys. Chem. Chem. Phys. 2016, 18, 19557.

11. G. M. Whitesides and D. J. Lipomi, Faraday Discussion 2009, 143, 373.

12. D. Lombardo, P. Calandra, E. Bellocco, G. Laganà, D. Barreca, S. Magazù, U. Wanderlingh and M. A. Kiselev, BBA-Biomembranes, 2016, 1858, 2769.

13. C. N. Likos, Phys. Rep., 2001, 348, 267.

14. M. Li, Z. Luo and Y. Zhao, Chem. Mater., 2018, 30, 25.

15. Y. Wang, H. Xu and X. Zhang, Adv. Mater., 2009, 21, 2849.

16. D. Demus, J. Goodby, G. W. Gray, H. W. Spiess and V. Vill, "Handbook of Liquid Crystals", Wiley-VCH, Weinheim, 1998

17. Y. Chen, P. Ma and S. Gui, Bio. Med. Res. Int., 2014, ID 815981.

18. R. Zana, "Dynamics of Surfactant Self-Assemblies: Micelles, Microemulsions, Vesicles and Lyotropic Phases", R. Zana (Ed.), Taylor \& Francis, London, 2005.

19. V. De Giorgio and M. Corti, "Physics of Amphiphiles: Micelles, Vesicles and Microemulsions", North-Holland, 1985.

20. F. Evans and H. Wennerström, "The Colloidal Domain", second edition, Wiley, New York, 1999.

21. D. L. Feldheim and C. A. Fossy Jr. (Eds.), "Metal Nanoparticle - Synthesis, Characterizations and Applications", Marcel Dekker, Inc., New York, Basel, 2002, ISBN 0-8247-0604-8.

22. J. Eastoe, M. J. Hollamby and L. Hudson, Adv. Colloid Interfac., 2006, 128-130, 5.

23. A. Das, T. Li, K. Nobusada, Q. Zeng, N. L. Rosi and R. Jin, J. Am. Chem. Soc. 2012, 134, 20286.

24. J. N. Israelachvili, "Thermodynamic and geometric aspects of amphiphile aggregation into micelles, vesicles and bilayers, and the interactions between them", in "Physics of Amphiphiles: Micelles, Vesicles and Microemulsions", V. Degiorgio and M. Corti (Eds.), North-Holland, Amsterdam, The Netherlands, 1985 , p. 24-58.

25. J. N. Israelachvili, "Intermolecular and Surface Forces", Academic Press, New York, NY, USA, 2nd edition, 1992.

26. J. Katsaras and T. Gutberlet, "Lipid Bilayers Structure and Interactions", Springer, Berlin, Germany, 2001.

27. J. M. Seddon and R. H. Templer, "Polymorphism of lipidwater systems", in "Handbook of Biological Physics", R. Lipowsky and E. Sackmann (Eds.), Elsevier Science Publisher BV, 1995, vol. 1, chapter 3, p. 97-160,

28. M. Kotlarchyk, S.-H. Chen, J. S. Huang and M. W. Kim, Phys. Rev. A, 1984, 29, 2054.

29. V. A. Frolov, A. V. Shnyrova and J. Zimmerberg, CSH Perspect. Biol., 2011, 3, Article ID a004747.

30. R. A. Karjiban, N. S. Shaari, U. V. Gunasakaran and M. Basri, J. Chem., 2013, Article ID 931051.

31. M. A. Kiselev, P. Lesieur, A. M. Kisselev, D. Lombardo, M. Killany, S. Lesieur and M. Ollivon, Nucl. Instrum. Meth. A, 2001, 470, 409.

32. P. Schurtenberger, Curr. Op. Coll\&Interface Sci., 1996, 1, 773.

33. S. Buček, S. Kralj and T. J. Sluckin, Adv. Cond. Matter Phys., 2015, Article ID 834867.

34. M. L. H. Green and G. Parkin, J. Chem. Ed., 2014, 91, 807.
35. R. G. Pearson, J. Chem. Ed., 1987, 64, 561.

36. R. J. Lundgren and M. Stradiotto, "Key Concepts" in "Ligand Design: An Introduction, chapter 1 in Ligand Design in Metal Chemistry: Reactivity and Catalysis", First Edition, M. Stradiotto and R. J. Lundgren (Eds.), John Wiley \& Sons, Ltd. Published 2016 by John Wiley \& Sons, Ltd., 2016.

37. A. Nimmermark, L. Ohrstrom and I. J. Reedijk, $Z$. Kristallogr., 2013, 228, 311.

38. I. D. Brown, "The chemical bond in inorganic chemistry: the bond valence model", Oxford University Press: Oxford; New York, 2002.

39. O. M. Yaghi, M. O'Keeffe, N. W. Ockwig, H. K. Chae, M. Eddaoudi and J. Kim, Nature, 2003, 423, 705.

40. P. Calandra, A. Longo, A. Ruggirello and V. Turco Liveri, $J$. Phys. Chem. B, 2004, 108, 8260.

41. P. Calandra, C. Giordano, A. Ruggirello and V. Turco Liveri, J. Colloid Interf. Sci., 2004, 277, 206.

42. K. Bian, H. Schunk, D. Ye, A. Hwang, T. S. Luk, R. Li, Z. Wang and H. Fan, Nat. Commun., 2018, 9, 2365.

43. S. Ortega, M. Ibanez, Y. Liu, Y. Zhang, M. V. Kovalenko, D. Cadavid and A. Cabot, Chem. Soc. Rev., 2017, 46, 3510.

44. Y. Yin and A. P. Alivisatos, Nature, 2004, 437, 664.

45. J. Kim, H. S. Kim, N. Lee, T. Kim, H. Kim, T. Yu, I. C. Song, W. K. Moon and T. Hyeon, Angew. Chem. Int. Ed., 2008, $47,8438$.

46. J. Kim, J. E. Lee, J. Lee, J. H. Yu, B. C. Kim, K. An, Y. Hwang, C. H. Shin, J. G. Park, J. Kim and T. Hyeon, J. Am. Chem. Soc., 2006, 128, 688.

47. J. Ge, Y. Hu, M. Biasini, W. P. Beyermann and Y. Yin, Angew. Chem. Int. Ed., 2007, 46, 4342.

48. H. Fan, A. Wright, J. Gabaldon, A. Rodriguez, C. J. Brinker and Y.-B. Jiang, Adv. Funct. Mater., 2006, 16, 891.

49. Z. Lu and Y. Yin, Chem. Soc. Rev., 2012, 41, 6874.

50. W. Wei, F. Bai and H. Fan, iScience 2019, 11, 272.

51. G. M. Ritcey and A. W. Ashbrook, "Hydrometallurgical extraction", in "Hand. Sept. Tech. Chem. Eng.", P. A. Schweitzer (Ed.), New York: Mc Graw-Hill, 1979, p. 2/1052/130.

52. K. Youshizuka, M. Koba and K. Inoue, "Solvent extraction of rare earth elements with bis (4-ethylcyclohexyl) phosphoric acid", in "Solvent extraction in the process Industries", D. H. Logsdail and M. J. Slater (Eds.), Proc. ISEC '93, York: Elsevier Appl. Sci., 1993, p. 242.

53. N. Zhou, J. Wu, Z. Yu, R. D. Neumann, D. Wang and G. Xu, Sci. China Ser. B, 1997, 40, 611.

54. J. Wu, N. Zhou, D. Wang, Z. Yu, R. D. Neumann and G. $\mathrm{Xu}$, Sci. China Ser. B, 1998, 40, 36.

55. Z. Yuan, Z. Yin, S. Sun and J. Hao, J. Phys. Chem. B, 2008, $112,1414$.

56. R. Talhout and J. B. F. N. Engbert, Langmuir, 1997, 13, 5001.

57. W. Guo, S. Chen, Y. Feng and C. Yang, J. Phys. Chem. C, 2007, 111, 3109.

58. P. Calandra, M. Cioni, V. La Parola and T. de Caro, "Atti dell'accademia peloritana dei pericolanti - classe di scienze fisiche matematiche e naturali", 2019, in press.

59. D. Lombardo, P. Calandra, S. Magazù, U. Wanderlingh, D. Barreca, L. Pasqua and M. A. Kiselev, Colloid Surface B, 2018, 170, 609 .

60. D. Lombardo, G. Munaò, P. Calandra, L. Pasqua and M. T. Caccamo, Phys. Chem. Chem. Phys., 2019, 21, 11983.

61. C. Wang, Z. Wang and X. Zhang, Acc. Chem. Res., 2012, 45,608 .

62. S. Zhang, Nat. Biotechnol., 2003, 21, 1171. 
63. J. M. Lehn, Proc. Natl. Acad. Sci. USA, 2002, 99, 4763.

64. S. Jain and F. S. Bates, Science, 2003, 300, 460.

65. L. Bonaccorsi, P. Calandra, M. A. Kiselev, H. Amenitsch and E. Proverbio, Langmuir, 2013, 29, 7079.

66. K. Rajagopal and J. P. Schneider, Curr. Opin. Struc. Biol., 2004, 14, 480-486.

67. M. G. Ryadnov and D. N. Woolfson, Nat. Mater., 2003, 2, 329.

68. P. Calandra, V. T. Liveri, A. M. Ruggirello, M. Licciardi, D. Lombardo and A. Mandanici, J. Mater. Chem. C, 2015, 3, 3198.

69. P. Calandra, A. Ruggirello, A. Pistone and V. T. Liveri, J. Clust. Sci., 2010, 21, 767.

70. A. Petitjean, L. A. Cuccia, J. M. Lehn, H. Nierengarten and M. Schmutz, Angew. Chem. Int. Ed. Engl., 2002, 41, 1195.

71. N. P. Galkin, B. N. Sudarikov, U. D. Veryatin, Y. D. Shishkov and A. A. Maiorov, "Technology of Uranium", 1st edition; Israel Program for Scientific Translations: Jerusalem, 1966.

72. J. R. Kumar, J.-S. Kim, J.-Y. Lee and H.-S. Yoon, Sep. Purif. Rev., 2011, 40, 77.

73. A. C. Vogel, "Vogel's Practical Organic Chemistry", 1974, p. 304.

74. S. Mishra, J. Dwivedi, A. Kumar and N. Sankararamakrishnan, New J. Chem., 2016, 40, 1213.

75. R. Zheng, S. Bao, Y. Zhang and B. Chen, Minerals, 2018, 8, 206.

76. L. Diab, U. Gellrich and B. Breit, Chem. Comm., 2013, 49, 9737.

77. T. Miyazawa, T. Endo and M. Okawara, J. Org. Chem., $1985,50,5389$.

78. M. Tokunaga, H. Aoyama, J. Kiyosu, Y. Shirogane, T. Iwasawa, Y. Obora and Y. Tsuji, J. Organomet. Chem., 2007, 692, 472.

79. J. Tsuji, T. Nagashima, N. T. Qui and H. Takayanagi, Tetrahedron, 1980, 36, 1311.

80. C. Magne, M. Urien, I. Ciofini, T. Tugsuza and T. Pauporté, RSC Advances, 2012, 2, 11836.

81. J. W. Clarck, C. V. Va, A. L. Wilson and P. Pa, "Process for preparing branched-chain aliphatic secondary amines"; Patent US2319848, 1943.

82. M. Goto, F. Kubota and Y. Baba, "Indium extraction agent and Indium extraction method", Patent US9376734B2, 2016.

83. B. Dietrich, J. M. Lehn and J. P. Sauvage, Tetrahedron,1973, 29, 1647.

84. S. K. Menon, S. V. Hirpara and U. Harikrishnan, Rev. Anal. Chem., 2004, 23, 233.

85. C. Galli and L. Mandolini, Chem. Commun., 1982, 251

86. A. H. Alberts, R. Annunziata and J. M. Lehn, J. Am. Chem. Soc., 1977, 99, 8502.

87. J. Cheney, J. M. Lehn, J. P. Sauvage and M. E. Stubbs, Chem. Commun., 1972, 1100.

88. S. Kulstaad and L. A. Malmsten, Tetrahedron Lett., 1980, 643.

89. R. Annunziata, F. Montanari, S. Quici and M. T. Vitali, Chem. Commun., 1981, 777.

90. W. Baker, J. F. W. McOmie and W. D. Ollis, J. Chem. Soc., 1951, 200.

91. G. Das, P. Tripathi, A. Tripathi and P. K. Bhardwaj, Tetrahedron, 2000, 56, 1501.

92. G. Das, P. Ghosh and P. K. Bharadwaj, Langmuir, 1997, 13, 3582.

93. G. Das and P. K. Bharadwaj, Langmuir, 2000, 16, 1910.

94. S. L. Chen and C. W. Frank, Langmuir, 1989, 5, 978.
95. P. Bandyopadhyay and P. Bhunia, Colloids Surf., B, 2007, $58,14$.

96. B. Sarkar, R. K. Gupta, R. A. Singh and P. K. Bharadwaj, Bull. Mater. Sci., 2008, 31, 517.

97. P. Bandyopadhyay and P. K. Bharadwaj, Langmuir, 1998, $14,7537$.

98. Y. Ishikawa, T. Kunitake, T. Matsuda, T. Otsuka and S. Shinkai, J. Chem. Soc., Chem. Commun., 1989, 11, 736.

99. K. Yagi, S. B. Khoo, M. Sugawara, T. Sakaki, S. Shinkai, K. Odashima and Y. Umezawa, J. Electroanal. Chem., 1996, 401, 65 .

100. P. Shahgaldian, U. Pieles and M. Hegner, Langmuir, 2005, 21,6503 .

101. L. Zhang, Y. Zhang, H. Tao, X. Sun, Z. Guo and L. Zhu, Thin Solid Films, 2002, 413, 224.

102. P. Timmerman, W. Verboom and D. N. Reinhoudt, Tetrahedron, 1996, 52, 2663.

103. L. Mandolini and R. Ungaro (Eds.), "Calixarenes in Action", Imperial College Press, Singapore, 2000, p. 271.

104. Z. Asfari, V. Bohmer, J. Harrowfield and J. Vicens (Eds.), "Calixarenes", Kluwer Academic Publishers, The Netherlands, 2001, p.683.

105. Y. Aoyama, Y. Tanaka and S. Sugahara, J. Am. Chem. Soc., 1989, 111, 5397.

106. O. Manabe, K. Asakura, T. Nishi and S. Shinkai, Chem. Lett., 1990, 1219.

107. R. V. Rodik, V. I. Boyko and V. I. Kalchenko, Curr. Med. Chem., 2009, 16, 1630 .

108. D. T. Schuhle, J. A. Peters, J. Schatz, Coord. Chem. Rev., 2011, 255, 2727.

109. G. M. Whitesides, J. P. Mathias and C. T. Seto, Science, 1991, 254, 1312-1319.

110. F. Perret, A. N. Lazar and A. W. Coleman, Chem. Commun., 2006, 2425.

111. A. W. Coleman, F. Perret, A. Moussa, M. Dupin, Y. Guo and H. Perron, Top. Curr. Chem., 2007, 277, 31.

112. F. Perret and A. W. Coleman, Chem. Commun., 2011, 47, 7303.

113. S.-B. Junga, C. Kimb and Y.-S. Kwona, Thin Solid Films, 2003, 438-439, 27.

114. T. Wei, C. Chen, J. Liu, C. Liu, P. Posocco, X. Liu, Q. Cheng, S. Huo, Z. Liang and M. Fermeglia, Proc. Natl. Acad. Sci. U. S. A., 2015, 112, 2978.

115. X. Liu and I. Gitsov, Macromolecules, 2018, 51, 5085.

116. A. Butler and R. M. Theisen, Coord Chem Rev., 2010, 254, 288.

117. T. Owen, S. M. Webb and A. Butler, Langmuir, 2008, 24, 4999.

118. K. M. Koczkur, S. Mourdikoudis, L. Polavarapu and S. E. Skrabalak. Dalton Trans., 2015, 44, 17883.

119. D. G. Kurth and M. Higuchi, Soft Matter, 2006, 2, 915.

120. A. S. Knight, J. Larsson, J. M. Ren, R. B. Zerdan, S. Seguin, R. Vrahas, J. Liu, G. Ren and C. J. Hawker, J. Am. Chem. Soc., 2018, 140, 1409.

121. A. De Nino, L. Maiuolo, P. Merino, M. Nardi, A. Procopio, D. Roca-Lopez, B. Russo and V. Algieri, ChemCatChem, 2015, 7, 830 .

122. M. L. Di Gioia, P. Costanzo, A. De Nino, L. Maiuolo, M. Nardi, F. Olivito and A. Procopio, RSC Adv., 2017, 7, 36482.

123. A. De Nino, P. Merino, V. Algieri, M. Nardi, M. L. Di Gioia, B. Russo, M. A. Tallarida and L. Maiuolo, Catalysts, 2018, 8, 364.

124. L. Maiuolo, B. Russo, V. Algieri, M. Nardi, M. L. Di Gioia, M. A. Tallarida and A. De Nino, Tetrahedron Lett., 2019, 60,672 . 
125. K. Ghandi, Green and Sustainable Chemistry, 2014, 4, 44.

126. M. Petkovic, K. R. Seddon, L. P. N. Rebelo and C. S. Pereira, Chem. Soc. Rev., 2011, 40, 1383.

127. J. Stoimenovski, P. M. Dean, E. I. Izgorodina and D. R. MacFarlane, Faraday Discuss., 2012, 154, 335.

128. D. Wang, C. Richter, A. Ruhling, P. Drcker, D. Siegmund, N. Metzler-Nolte, F. Glorius and H.-J. Galla, Chem. Eur. J., 2015, 21,1 .

129. K. Goossens, K. Lava, C. W. Bielawski and K. Binnemans, Chem. Rev., 2016, 116, 4643.

130. M. A. Spirache, C. Cretu, L. Cseh, V. Sasca, V. Badea, R. Tudose, L. N. Develeseanu-Corici, O. Costisor and E. I. Szerb, Rev. Roum. Chim., 2018, 63, 521.

131. Y. Ren, J. Zhang, J. Guo, F. Chen and F. Yan, Macromol. Rapid Commun., 2017, 38, 1700151.

132. V. Balzani, M. Venturi and A. Credi, "Molecular Devices and Machines - A Journey into the Nanoworld", WileyVCH: Weinheim, 2008.

133. C. Giansante, P. Ceroni, V. Balzani and F. Vögtle, Angew. Chem. Int. Ed., 2008, 47, 5422.

134. D. M. Vriezema, M. C. Aragonès, J. A. A. W. Elemans, J. J. L. M. Cornelissen, A. E. Rowan and R. J. M. Nolte, Chem. Rev., 2005, 105, 1445.

135. S. Bhattacharya and N. Kumari, Coord. Chem. Rev., 2009, $253,2133$.

136. N. C. Gianneschi, M. S. Masar III and C. A. Mirkin, Acc. Chem. Res., 2005, 38, 825.

137. A. C. Mendes, E. T. Baran, R. L. Reis and H. S. Azevedo, WIREs Nanomed. Nanobiotechnol., 2013, 5, 582.

138. C. Rubén, O. Enrique, H. J. Bolink, M. Filippo, A. Gianluca and A. Nicola, Angew. Chem. Int. Ed. 2012, 51, 8178.

139. D. Aiello, A. M. Talarico, F. Teocoli, E. I. Szerb, I. Aiello, F. Testa and M. Ghedini, New J. Chem. 2013, 37, 1486.

140. B. Donnio, Curr. Opin. Solid St. M., 2002, 7, 371.

141. M. Mauro, G. De Paoli, M. Otter, D. Donghi, G. D’Alfonso and L. De Cola, Dalton Trans., 2011, 40, 12106.
142. Đ. Težak, S. Popović, S. Heimer and E. Strajnar, Progr. Colloid. Polym. Sci., 1989, 79, 293.

143. D. Domínguez-Gutiérrez, G. De Paoli, A. GuerreroMartínez, G. Ginocchietti, D. Ebeling, E. Eiser, L. De Cola and C. J. Elsevier, J. Mater. Chem.,2008, 18, 2762.

144. T. Owen and A. Butler, Coord. Chem. Rev., 2011, 255, 678.

145. C. A. Strassert, M. Mauro and L. De Cola, Adv. Inorg. Chem., 2011, 63, 47.

146. J. Bowers, M. J. Danks and D. W. Bruce, Langmuir, 2003, 19, 292.

147. J. Bowers, K. E. Amos and D. W. Bruce, Langmuir, 2005, 21, 5696.

148. C. Draeger, C. Böttcher, C. Messerschmidt, A. Schulz, L. Ruhlmann, U. Siggel, L. Hammarström, H. BerglundBaudin and J.-H. Fuhrhop, Langmuir, 2000, 16, 2068.

149. Y. Li, L. Chen, Y. Ai, E. Y.-H. Hong, A. K.-W. Chan and V. W.-W. Yam, J. Am. Chem. Soc., 2017, 139, 13858.

150. Y. Atoini, E. A. Prasetyanto, P. Chen, S. Silvestrini, J. Harrowfield and L. De Cola, Chem. Eur. J., 2018, 24, 12054.

151. S. Carrara, A. Aliprandi, C. F. Hogan and L. De Cola, J. Am. Chem. Soc., 2017, 139, 14605.

152. M. de Barros e Silva Botelho, J. M. Fernandez-Hernandez, T. Branquinho de Queiroz, H. Eckert, L. De Cola and A. S. Stucchi de Camargo, J. Mater. Chem., 2011, 21, 8829.

153. A. M. Talarico, M. Ghedini, C. Oliverio Rossi and E. I. Szerb, Soft Matter., 2012, 8, 11661.

154. A. M. Talarico, E. I. Szerb, M. Ghedini and C. Oliviero Rossi, Soft Matter., 2014, 10, 6783.

155. A. Palmioli, A. Aliprandi, D. Septiadi, M. Mauro, A. Bernardi, L. De Cola and M. Panigati, Org. Biomol. Chem., 2017, 15, 1686.

156. A. Guerrero-Martínez, Y. Vida, D. Domínguez-Gutiérrez, R. Q. Albuquerque and L. De Cola, Inorg. Chem., 2008, 47, 9131. 
